\title{
Eficacia de la musicoterapia en el bienestar psicológico y la calidad de vida en personas con discapacidad física y orgánica severa
}

\author{
Jaime Carrasco García ${ }^{1}$; Ignacio González López²; Ana Belén Cañizares Sevilla ${ }^{3}$
}

Recibido: 29 de junio de 2020 / Aceptado: 4 de febrero de 2021

Resumen. La musicoterapia consiste en la utilización de la música a cargo de un profesional formado que tiene como objetivo mejorar el bienestar físico, emocional, social, cognitivo y psicológico de las personas. La presente investigación, basada en un diseño mixto cuasiexperimental con pre-test y pos-test con un solo grupo, se propone determinar los efectos que produce la musicoterapia en pacientes con discapacidad física y orgánica severa. Las necesidades de estos/as pacientes son tanto de tipo físico como psicológico, social y espiritual, y pueden ser abordadas desde el campo de la musicoterapia, ya que la música usada con intención terapéutica puede llegar a satisfacerlas. Los resultados evidencian que su aplicación es una opción no-farmacológica que resulta muy eficaz para una mejor autoaceptación de su situación, unas relaciones más positivas con sus compañeros/as del grupo de intervención y los que les rodean, crecimiento personal, un propósito de vida $\mathrm{y}$, por ende, una mejor calidad de vida percibida, en consonancia con investigaciones realizadas en innumerables contextos y por equipos interdisciplinares.

Palabras clave: musicoterapia; discapacidad física y orgánica severa; bienestar psicológico; calidad de vida; relaciones interpersonales.

\section{[en] Efficacy of music therapy in psychological well-being and quality of life in severely physically and organically disabled patients}

\begin{abstract}
Music therapy is the use of music to improve the physical, emotional, social, cognitive and psychological wellbeing. The current research, based on a mixed quasi-experimental design with pre-test and post-test with a single group, aims to determine the effects of music therapy in patients with severe physical and organic disabilities. The needs of these patients are both physical, psychological, social and spiritual, and can be addressed from the field of music therapy, since music used for therapeutic purposes can satisfy them. The results show that its application it turns out to be effective as a non-pharmacological option in better self-acceptance of your situation, more positive relationships with your peers in the intervention group, and those around them, greater personal growth, a better life purpose and, therefore, a better perceived quality of life. This is in line with research carried out in countless contexts and by interdisciplinary teams.

Keywords: music therapy; severe physical and organic disability; psychological well-being; quality of life; autonomy; interpersonal relationships.
\end{abstract}

Sumario. 1. Introducción. 2. Método. 2.1. Objetivos. 2.2. Variables de estudio. 2.3. Grupo Informante. 2.4. Instrumentos de medida. 2.5. Procedimiento. 2.6. Programa de Musicoterapia. 3. Resultados. 3.1. Valoración del Bienestar Psicológico. 3.2. Valoración de la efectividad de la intervención. 4. Discusión y conclusiones. 5. Referencias bibliográficas. 6 . Anexo 1. 7. Anexo 2.

Cómo citar: Carrasco, J., González, I. y Cañizares, A. B. (2021). Eficacia de la musicoterapia en el bienestar psicológico y la calidad de vida en personas con discapacidad física y orgánica severa. Revista Electrónica Complutense de Investigación en Educación Musical, 18, 195-215. http://dx.doi.org/10.5209/reciem.70347

\footnotetext{
Facultad de Ciencias de la Educación y Psicología. Universidad de Córdoba, España

E-mail: m62cargj@uco.es

https://orcid.org/0000-0003-4399-3850

2 Facultad de Ciencias de la Educación y Psicología. Universidad de Córdoba, España.

E-mail: ed1goloi@uco.es

https://orcid.org/0000-0002-9114-4370

3 Facultad de Ciencias de la Educación y Psicología. Universidad de Córdoba, España

E-mail: eo1casea@uco.es

https://orcid.org/0000-0002-1747-9500
}

Rev. electrón. complut. inves. educ. music. 18, 2021: 195-215 


\section{Introducción}

Esta propuesta de intervención musicoterapéutica encuentra su justificación, por un lado, en el incremento en la sociedad actual de personas con diversidad funcional como consecuencia de accidentes traumáticos (craneoencefálicos o medulares), encefalopatías, accidentes cardiovasculares o parálisis cerebral, y, por otro, investigar sobre el valor de la música como terapia y para contribuir en la mejora de estas situaciones. Son personas que, en líneas generales, se caracterizan por una disminución o alteración del estado de conciencia, de las habilidades cognitivas o del funcionamiento físico, con dificultades motoras (movilidad y coordinación, dificultad para articular sonidos y palabras) y/o sensoriales (visión, audición, tacto y gusto), regulación y control de la conducta, dificultades de abstracción y resolución de problemas, trastornos de aprendizaje y memoria, así como disfunciones o problemas en el ámbito de la personalidad y el ajuste emocional.

Asimismo, todo trastorno y aparición súbita de este tipo de enfermedades provoca un desajuste crítico en el curso vital de la persona, así como en su entorno familiar y comunitario. Tal y como apuntan Bascones et al. (2005), el mundo cotidiano es bruscamente destruido y las posibilidades, los valores y las perspectivas de estos pacientes cambian por la descomposición familiar que suelen traer consigo. En esta línea, Moreno et al. (2006), subrayan que esta situación provoca cambios en sus vidas y las de sus familiares como consecuencia de la dependencia que producen las limitaciones físicas o mentales, el estado de salud, el cambio de rol o de actividades sociales. Debido a las pocas expectativas de futuro que tienen, se describen en términos negativos, lo que les provoca ansiedad y depresión.

En el grupo de la discapacidad física y orgánica severa se incluye a personas con:

1. Daño cerebral sobrevenido que se produce a raíz de una lesión cerebral. No es una discapacidad de nacimiento o degenerativa, pues tiene lugar como consecuencia de traumatismos craneoencefálicos que causan una disminución o alteración del estado de conciencia y conllevan una disfunción de las habilidades cognitivas o del funcionamiento físico (Bascones et al., 2005). También puede ser debido a un accidente cerebrovascular, con afectaciones transitorias o definitivas del funcionamiento de una o varias zonas del encéfalo (cerebro, cerebelo y tronco cerebral). Las alteraciones más frecuentes son las plejias/parálisis o debilidad total de la musculatura.

2. Enfermedades neurodegenerativas que conllevan la pérdida progresiva e imparable de neuronas en áreas concretas del cerebro y producen la esclerosis múltiple, la ataxia de Friedreich, la enfermedad de Huntington y Parkinson (Rodríguez-Antigüedad, 2004).

3. Lesión medular que afecta a la función motora, sensitiva y/o autonómica. Pueden ser producidas por traumatismos (paraplejias y tetraparesias): por accidentes de tráfico, deportivos, laborales y otros, o por lesiones medulares no traumáticas como la poliomielitis, las congénitas, las del desarrollo, por trastornos degenerativos y otros (Martín et al., 2013).

En el año 2005, la UNESCO lleva a cabo una Declaración Universal de principios bioéticos y Derechos Humanos que tiene tres niveles de relaciones: a) Los principios relacionados con la dignidad de la persona; b) Las libertades fundamentales, autonomía, el consentimiento; y, c) La confidencialidad. En dichos niveles, se hace hincapié en que la dignidad y los derechos exigen que los intereses y el bienestar de la persona prevalezcan sobre el interés exclusivo de la ciencia y de la sociedad. En España se materializa con la promulgación de la Ley 39/2006, de 14 de diciembre, de Promoción de la Autonomía Personal y Atención a las personas en situación de dependencia. Una legislación que "incorpora conceptos básicos para la vida independiente como la igualdad de oportunidades, la no discriminación, la figura del asistente personal y el pago directo" (Palacios y Romañach, 2006, p. 66).

El bienestar es el indicador central de la salud y está íntimamente relacionado con las emociones positivas, el optimismo, la calidad de vida, la dignidad (Blanco y Díaz, 2005). También se centra la calidad de vida en el bienestar subjetivo, el psicológico y el social (Alfaro et al., 2015). Así, el concepto de salud contiene de manera implícita el concepto de bienestar de las personas y no es solamente la ausencia de afecciones o enfermedades (Constitución de la OMS, 1946 y Conferencia Internacional sobre Atención Primaria de Salud Alma-Ata, 1978), sino que comprende también el bienestar físico, mental y social. Desde otro punto de vista, el bienestar es resultado de la evaluación cognitiva que las personas efectúan acerca de cómo les fue (o les está yendo) en el transcurso de su vida (Lombardo, 2013). Efectivamente, Okun y Stock (1987) sostienen que los indicadores del bienestar son subjetivos y Schwartzmann (2003, p. 1), reconocen que es "una noción eminentemente humana que se relaciona con el grado de satisfacción que tiene la persona con su situación física, su estado emocional, su vida familiar, amorosa, social, así como el sentido que le atribuye a su vida" (5). Por su parte, Montorio e Izal (1992) establecen cuatro dimensiones sobre este constructo: a) Afecto positivo (bienestar transitorio de carácter afectivo o emocional); b) Afecto negativo (insatisfacción transitoria de carácter afectivo o emocional); c) Felicidad (bienestar duradero que incluye principalmente un componente afectivo, aunque también una valoración positiva del mismo); $y$, d) Congruencia (bienestar duradero que implica un juicio o valoración global sobre la propia vida).

Sin embargo, para Meléndez et al. (2011), bienestar es el "grado en que una persona juzga de un modo general o global su vida utilizando el componente emocional o afectivo relacionado con el placer y/o displacer que experimenta" (p. 65). Está enlazado con un juicio subjetivo, global y relativamente estable de satisfacción con la vida y la moral de las personas (De Juanas et al., 2013). Si bien, los ámbitos objeto de satisfacción y de mayor interés para el 
ser humano son "el trabajo, la familia, la salud, las condiciones materiales de vida, las relaciones interpersonales, y las relaciones sexuales y afectivas con la pareja" (García, 2005, p. 4).

Pascual (1998) sostiene que la calidad de vida está compuesta no solo por las dimensiones subjetivas, sino también por unos componentes externos sociales y objetivos, como son la competencia conductual y la calidad del medio ambiente exterior que rodea a la persona. De otro lado, Everaert et al. (2020) sostienen que las emociones negativas se asocian con la menor presencia de emociones positivas.

Atendiendo a lo apuntado por Ryff (1989b), el bienestar psicológico es una actitud positiva ante la salud, aunque haya presencia de alguna enfermedad, y supone un compromiso con los cambios existenciales de la vida. Define seis dimensiones personales íntimamente relacionadas con las necesidades, motivos y atributos que cualquier persona, en un estado normal de salud, debe satisfacer para ser feliz: a) Capacidad de la persona de sentirse satisfecha consigo misma, autoaceptando sus propias limitaciones; b) Capacidad de mantener relaciones de confianza, estables y de intimidad con los demás; c) Dominio del entorno, controlando las responsabilidades y decisiones tomadas en el día a día; d) Autonomía, independencia y autodeterminación en sus decisiones; e) Crecimiento personal y autorrealización como persona; y, f) Tener un propósito en la vida, alguna meta por la que mirar y luchar, dándole sentido.

El crecimiento personal y los propósitos de vida disminuyen conforme pasa el tiempo, mientras la autonomía y dominio del ambiente aumentan a lo largo de la vida (Ruiz, 2012). En este punto se hace necesario destacar el trabajo de Díaz et al. (2006), con su adaptación española de las Escalas de Bienestar Psicológico de Ryff.

Las personas con discapacidad identifican su estado de salud con la presencia de dolor ocasionado por trastornos articulares severos, parálisis y déficits sensoriales y cognitivos, que les desencadenan temor e inseguridad para realizar actividades con autonomía. A las personas de más edad, la falta de perspectivas les despierta sentimientos de minusvalía, desesperanza e impotencia (Moreno et al., 2006).

Para las personas mayores con discapacidad, el sentimiento de bienestar consiste en tener una buena salud, planes de futuro, apoyo social, ingresos económicos y no tener depresión (Yanguas, 2006). En este sentido, el apoyo social, las actividades sociales, la forma de afrontar los problemas, los rasgos de personalidad, la autoestima, el estado funcional y la salud, influyen en las personas con discapacidad física y orgánica, por ello es muy importante afrontarlos para mejorar sus condiciones de salud, su funcionamiento físico y cognitivo, su afecto positivo y su participación (Fernández-Ballesteros et al., 2010). Precisamente, para poder experimentar bienestar psicológico y mejorar su calidad de vida, deben tener confianza, creer en sí mismas y en su propia capacidad, mostrar actitudes positivas hacia sí mismas y funcionar psicológicamente de forma más adecuada (Guil et al., 2016).

Como se deduce, la felicidad personal depende de todo lo que nos rodea (Hervás, 2009) y se hace necesario proponer una nueva generación de derechos sociales que dignifiquen al ser humano (Escarbajal et al., 2014).

Numerosos autores coinciden en los beneficios de la música cuando se usa para mejorar el bienestar de la persona, poniendo el énfasis en que la musicoterapia es un proceso sistemático que tiene como finalidad ayudar al cliente a llegar a la salud. En el mismo intervienen: a) El paciente, usuario/a o cliente que necesita la ayuda; b) El o la musicoterapeuta que lo atiende; c) Unos objetivos médico-curativos, psicoterapéuticos, recreacionales, educativos, etc.; y, d) Un tratamiento que se desarrollará en función de la orientación del musicoterapeuta, que velará por encauzar los problemas del paciente. Ya en 1989, Bruscia (2014, p. 21) definió la musicoterapia como "un proceso sistemático de intervención en el que el terapeuta ayuda al cliente para lograr la salud, utilizando experiencias musicales y las relaciones que se desarrollan a través de ellos como fuerzas dinámicas de cambio". En esta línea, ayuda al ser humano en su función preventiva y curativa (Poch, 2001) y es una herramienta terapéutica (Lago, 2008).

La literatura relacionada con investigaciones realizadas en el campo de la musicoterapia avala la evidencia del influjo de la música, usada con intención terapéutica, sobre el bienestar psicológico (Ryff, 1989a), social (Keyes, 1998) y emocional (Benedito, 2010), o sobre la calidad de vida de las personas que están sanas, satisfaciendo, además, las necesidades de niños/as y adultos con discapacidades o enfermedades (American Music Therapy Association, 2014).

El importante papel asignado a la música ya fue establecido por Gaston (1982):

La música es una forma de comportamiento humano que ejerce una influencia única y poderosa. A través de ella, los enfermos y deficientes pueden modificar su conducta, sea adquiriendo nuevas pautas o mejorando las que ya tienen. A veces es la música misma la que lo provoca, pero la mayoría de las veces es el musicoterapeuta el que influye para que se realicen esas modificaciones. Ya sea mediante la música o la persuasión lo que se busca es siempre producir cambios deseables (p. 27).

Para la World Federation of Music Therapy (1996), la Musicoterapia es una profesión sanitaria establecida que usa la música para hacer frente a necesidades físicas, emocionales y sociales de individuos de todas las edades. Las intervenciones pueden ser diseñadas para promover el bienestar, manejar el estrés, aliviar el dolor, expresar sentimientos, potenciar la memoria, mejorar la comunicación o promover la rehabilitación en un tratamiento.

Es definida por Poch (2001), como "la aplicación científica del arte de la música y la danza con finalidad terapéutica, para prevenir, restaurar y acrecentar la salud tanto física como mental y psíquica del ser humano, a través de la acción del musicoterapeuta" (p. 93). Dado que la calidad de vida es un sistema de valores donde predomina la necesidad de desarrollo personal, de autorrealización y de unos estilos de vida más armoniosos y sociales (Seoane, 1999), se defiende el uso profesional de la musicoterapia en entornos médicos, educativos y cotidianos con personas 
que buscan optimizar su calidad de vida y mejorar su salud y bienestar físico, social, emocional, intelectual y espiritual (Soria et al., 2011).

Benenzon (2011) la establece en su modelo como una psicoterapia no-verbal que utiliza las expresiones corpóreo-sonoras no-verbales para desarrollar un vínculo relacional entre musicoterapeuta y otras personas necesitadas de ayuda, para mejorar el bienestar y la calidad de vida. La considera como un proceso histórico-vincular (a lo largo de una serie de encuentros con comienzo, trayectoria y final), dentro de un contexto no-verbal, entre el terapeuta y paciente o grupo de pacientes.

Según Vaillancourt (2009), la musicoterapia tiene como objetivo "restaurar, mantener o mejorar el bienestar físico, emocional, social, cognitivo y psicológico de una persona" (p. 50). Existe evidencia de que afecta al nivel psicofisiológico y emocional, debido a que la música modifica las endorfinas y las células $\mathrm{C}$ del organismo, que forman parte del sistema inmunológico (Lacárcel, 2003) y disminuye significativamente los niveles de amilasa y su capacidad de reducir el estrés y contribuir a mejorar el bienestar general (Poquérusse et al., 2018).

De manera muy activa, el musicoterapeuta se orienta a provocar en el paciente respuestas emocionales de manera más directa e inmediata que otras terapias verbales tradicionales. La consideración de forma terapéutica de comunicación no-verbal, que utiliza el lenguaje corporal y simbólico, que se aplica a la prevención, diagnóstico y tratamiento de posibles dificultades o trastornos que presentan las personas, permite la observación y obtención de respuestas distintas (Palacios, 2001).

En la actualidad, las investigaciones llevadas a cabo tanto por equipos médicos como por musicoterapeutas, avalan la eficacia de la musicoterapia en diferentes campos clínicos. En el caso de pacientes con Alzheimer, Gómez y Gómez (2017) encuentran que "mejora algunas de las alteraciones cognitivas, psicológicas y conductuales, aunque sería interesante complementar la musicoterapia con intervenciones de danzaterapia a fin de mejorar los aspectos motores y funcionales" (p. 300).

En el campo de la demencia, Fakhoury et al. (2017) observan que las intervenciones musicoterapéuticas disminuyen fuertemente la ansiedad y tienen el potencial de mejorar la calidad de vida. Holden et al. (2019) sostienen que, aplicada en el hogar, ayuda a reforzar un grado de independencia a estos pacientes y sus cuidadores, permitiendo una traducción directa de beneficios a su vida diaria. Lam et al. (2020) encuentran que "podría mejorar la fluidez verbal y reducir la ansiedad, la depresión y la apatía en pacientes con demencia, aunque no parece haber beneficios comprobados en memoria, función diaria o calidad de vida en general. Se necesitan más ensayos clínicos” (p. 9).

En relación a las personas que sufren de aislamiento y sensación de inestabilidad, Bradt et al. (2019) evidencian que la técnica de composición de canciones favorece la expresión de sentimientos y la toma de conciencia relacional.

Durante el procedimiento, potencialmente doloroso, de las inserciones intravenosas y extracciones de sangre, Mandel et al. (2019) encuentran que produce beneficios en el estrés y el dolor frente a los pacientes que no reciben musicoterapia. Igualmente, en enfermos graves hospitalizados, Fallek et al. (2020) demuestran que es una intervención accesible y adaptable, ya que los pacientes se muestran interesados, receptivos y satisfechos. En el dolor crónico, Low et al. (2020) sugieren que proporciona beneficios en las áreas de autoeficacia, depresión y capacidad para participar en actividades sociales, y en enfermos con cáncer, Köhler et al. (2020) descubren un impacto positivo en el bienestar, la ansiedad, la depresión, estado de ánimo y dolor con intervenciones de relajación e imágenes, canto e improvisación con instrumentos factibles de tocar.

Finalmente, en un estudio de análisis documental sobre investigaciones con pacientes oncológicos, se obtiene como resultado que en situaciones de tipo emocional reduce la depresión, la ansiedad y el estrés, ayudando en la relajación y mejorando el umbral del dolor; por lo cual se debiera conducir a una implantación cada vez más normalizada de la musicoterapia en los centros hospitalarios (Carrasco et al., 2020).

En lo concerniente a investigaciones sobre el tema que nos ocupa, y en cuanto al accidente cerebrovascular, Särkämö et al. (2008) encuentran que escuchar música de forma regular puede mejorar la recuperación cognitiva y prevenir estados de ánimo negativos. En el mismo sentido se pronuncia Vargas (2009) que encontró que el escuchar música durante el estado temprano post-derrame cerebral puede reforzar la recuperación cognoscitiva y prevenir una conducta negativa. En niños con discapacidades neurológicas, López (2009) habla del impacto que les produce la musicoterapia. Ciertamente, escuchar música ayuda a regular la frecuencia cardíaca y al trastorno por estrés postraumático (Osborne, 2012).

En cuanto a pacientes con esquizofrenia, se mencionan mejoras en su percepción de bienestar y calidad de vida, del ánimo y la ansiedad (Kwan y Clift, 2018), resultando una terapia coadyuvante para reducir síntomas negativos (Talwar et al., 2006).

Así mismo, en pacientes con depresión, Guenoun y De Pedro (2014) concluyen que produce beneficios emocionales, disminuyendo la ansiedad y el estrés. Silverman (2014) alude a un mejor manejo de la depresión, vigor, confusión, tensión y fatiga. En efecto, Cabral et al. (2014) encuentran una disminución de la ansiedad en cuidadores y reduce la ansiedad y la depresión en adultos chinos presos (Chen et al. 2014). En esta línea se suceden las investigaciones de Meadows et al. (2015), Werner et al. (2016), Aalbers et al. (2017) y Burns et al. (2018). 


\section{Método}

\subsection{Objetivos}

El presente artículo se propone investigar los efectos que produce la musicoterapia sobre un grupo de pacientes con discapacidad física y orgánica severa, para propiciar el desarrollo del bienestar, como determinante de una mejor salud y calidad de vida. Ello da lugar a los siguientes objetivos específicos:

- Describir el efecto sobre el bienestar psicológico de usuarios/as con discapacidad física y orgánica severa, tras una intervención musicoterapéutica basada en la improvisación no-verbal, siguiendo el Modelo Benenzon.

- Evaluar el efecto de la intervención en la calidad de vida de los usuarios/as.

\subsection{Variables de estudio}

Planteado el objetivo de esta investigación se procede a especificar las variables utilizadas para darle respuesta, configurando un total de siete elementos distribuidos en:

- Variables dependientes: autoaceptación, autonomía, relaciones positivas, dominio del entorno, crecimiento personal y propósito en la vida.

- Variable independiente: sexo.

\subsection{Grupo Informante}

El grupo de trabajo estaba compuesto por 7 hombres y 3 mujeres de la Residencia para personas con discapacidad gravemente afectadas de FEPAMIC (Federación Provincial de Asociaciones de Personas con Discapacidad Física y Orgánica de Córdoba, España), que siguen conservando de forma aceptable su capacidad de comunicación y reflexión. Sin embargo, dado que su motricidad fina se encuentra muy deteriorada, a la hora de rellenar las escalas para obtener datos de la intervención musicoterapéutica, tuvieron que ser ayudados por el terapeuta. Las edades estaban comprendidas entre 37 y 60 años, con una edad media de 47 años. Respecto a su nivel educativo, un $60 \%$ de los sujetos no tienen estudios, el $30 \%$ posee primarios y un $10 \%$ de bachillerato.

Los/las participantes padecen enfermedades como hemiplejia izquierda, encefalopatía epileptiforme postraumática, parálisis cerebral, tetraparesia, depresión, neurosis fóbica, tetraparesia espástica y epilepsia, parálisis infantil, hemiplejia y leve retraso mental entre otras, pero conservan de una manera aceptable sus capacidades de comunicación y reflexión. En la Tabla 4 del Anexo 1 se muestra de manera sintetizada la descripción de los datos clínicos, edad, nivel de estudios, diagnóstico, etiología y tratamiento. La única condición para ser incluido en la muestra fue que conservasen de forma aceptable su capacidad de comunicación y reflexión.

Todas ellas son razones suficientes para tomar en consideración y poner en práctica esta investigación, ya que hay numerosas investigaciones que han centrado sus esfuerzos en analizar los beneficios de la musicoterapia: en la Educación Especial (Poch, 2001; Ortega et al., 2009); en la adolescencia (Benedito, 2010 y López, 2015); para todas las personas en general (Oslé, 2011); en la mejora de la dislexia (Overy et al., 2003) o en pacientes con cáncer (Martí et al., 2015a), entre otros muchos estudios.

La intervención se llevó a cabo, tras la firma del contrato de conformidad entre la dirección del Centro (FEPAMIC) y el musicoterapeuta, respetando las cuestiones éticas fundamentales recogidas en las principales guías y códigos de ética científica, como la Declaración de Helsinki (Manzini, 2000) o códigos más adaptados a las ciencias sociales, como el ESRC Framework for Research Ethics (Orton-Johnson, 2010). Esto implica que todos los participantes tienen que dar su consentimiento tanto para la recogida como para el tratamiento de la información obtenida. A continuación, se desglosan los principios que se han tenido en cuenta para llevar a cabo este trabajo: No dañar a los participantes de la investigación. La independencia de la investigación debe ser clara y cualquier conflicto de intereses o parcialidad debe ser explícito. Se ha respetado, en todo momento, la confidencialidad de la información suministrada por los sujetos de investigación y el anonimato de los participantes. Participaron de manera voluntaria, sin ningún tipo de coerción. La investigación se diseñó, revisó y emprendió, garantizando la integridad y la calidad. Tanto la Dirección del Centro como los participantes estuvieron completamente informados sobre el propósito, los métodos y los posibles usos previstos de los resultados.

\subsection{Instrumentos de medida}

Con la finalidad de dar respuesta a esta investigación, se emplearon los siguientes instrumentos de recogida de información:

- Escala de Bienestar Psicológico de Ryff (1989a), adaptación al castellano de Díaz et al. (2006). Para mejorar las propiedades psicométricas de las escalas, estos autores desarrollaron una nueva versión reducida que facilita su 
aplicación y cuenta con unos niveles de consistencia que mejoran la original de Carol Ryff. Comprende un total de 39 ítems a los que los participantes deberán responder utilizando un formato de respuestas tipo Likert, con 6 opciones de respuestas de categorías ordenadas, con puntuaciones comprendidas entre 1 (totalmente en desacuerdo) y 6 (totalmente de acuerdo). Varios ítems están redactados en forma inversa para minimizar la conformidad. Están distribuidos en seis dimensiones (Autoaceptación: İ́tems 1, 7, 13, 19, 25, y 31. Relaciones positivas: İtems 2, 8, 14, 20, 26, y 32. Autonomía: Ítems 3, 4, 9, 10, 15, 21, 27, y 33. Dominio del entorno: Ítems 5, 11, 16, 22, 28, y 39. Crecimiento personal: Ítems 24, 30, 34, 35, 36, 37, y 38. Propósito en la vida: Ítems 6, 12, 17, 18, 23 y 29. y 39, y un factor de segundo orden denominado Bienestar Psicológico). La escala ha sido previamente aplicada en investigaciones anteriores: además de Díaz et al. (2006), por Abello et al. (2008), Zubieta y Delfino (2010), Zubieta et al. (2012) o Zubieta et al. (2012), entre otros, que trabajan con la Escala de Bienestar Psicológico y, por tanto, está dotada del rigor científico necesario. La misma se implementó en formato pre-test post-test, previa y posteriormente a la implementación de un programa de intervención musicoterapéutica.

- Debate: el propósito de esta herramienta fue propiciar la interacción mediante la conversación provocando el diálogo entre los usuarios/as, a fin de obtener información sobre su forma de pensar, sentir y vivir en torno a las variables trabajadas en cada una de las sesiones.

\subsection{Procedimiento}

Para la investigación se ha recurrido a la metodología de diseño mixto cuasiexperimental con pre-test - pos-test de un solo grupo. Su elección viene dada por la imposibilidad de aleatorización de los participantes, sin embargo, el problema planteado tiene precisión porque busca conocer los efectos del uso de la musicoterapia. Tiene importancia por la influencia del problema sobre la salud y la calidad de vida. Posee claridad porque define los términos usados, los dilucida y facilita su conocimiento y profundización en este campo. Aporta especificación porque sólo se refiere al uso de la música con intención terapéutica

El trabajo de campo consistió en una programación de intervención organizada en siete bloques, diseñados a partir de las 6 dimensiones de la Escala de Bienestar Psicológico de Ryff, más uno de adaptación al objeto intermediario. Se llevó a cabo tres veces por semana, con una duración de 2 horas (3 en la última sesión de cada bloque), en las dependencias de la institución, tomando como base las recomendaciones de Benenzon de que la frecuencia de trabajo no debe ser menor de tres veces por semana y, a poder ser, de manera permanente y continua. Se desarrollaron 35 sesiones con la finalidad de que el estudio se ajustase, en la medida de lo posible, a estas indicaciones.

\subsection{Programa de Musicoterapia}

El problema que se plantea en este estudio consiste en analizar la influencia de la práctica de la Musicoterapia, basada en la improvisación no-verbal siguiendo el Modelo Benenzon, en la salud y la calidad de vida percibida por las personas con discapacidad física y orgánica severa.

Si bien la intervención se basa en este Modelo de improvisación no-verbal, sonoro corporal libre (Benenzon, 2011), que permite el vínculo sonoro entre el musicoterapeuta y la persona y desemboca en una mejora de la calidad de vida de esta mediante la apertura de nuevos canales de comunicación, se han introducido variantes propias para optimizar las sesiones. Al no estar enfocada esta investigación desde una perspectiva clínica, se desarrolla con un grupo de usuarios/as con discapacidad física y orgánica severa que mantienen una capacidad verbal y de reflexión adecuadas al tipo de investigación que nos proponemos, al poder expresar sus sentimientos al finalizar cada bloque de sesiones. Buscamos una mejora en su calidad de vida a través de la recreación y/o el divertimento, utilizando todas las técnicas benenzonianas, pero adaptadas a la institución en la que nos desenvolvemos.

En el proceso, el musicoterapeuta, en su función de terapeuta no-verbal (al aplicar el objeto intermediario como mediador con el paciente/cliente) establece una secuencia energética, tal y como sigue:

- A través de sus expresiones no-verbales y de su personalidad, ayuda a liberar la tensión energética de los ISOs (identidad sonora-musical) del usuario/a.

- Esas descargas energéticas del usuario/a impactan en sus propios ISOs: ISO Universal (herencia sonora como ser humano), ISO Gestáltico (identidad sonora del propio individuo), ISO cultural (herencia cultural de la sociedad en la que vive el individuo) e ISO complementario (energías del individuo que se manifiestan en las relaciones con los otros).

- Como consecuencia, se propicia entre terapeuta y usuario/a el ISO en Interacción (produce el vínculo de la comunicación) que da lugar al advenimiento de: ISO Grupal, ISO Familiar (sonidos, movimientos y pausas que caracterizan a un grupo familiar), ISO Ambiental, ISO Comunitario y el ISO Transcultural.

- Mediante la comunicación no-verbal, se movilizan los ISOS del musicoterapeuta que elabora una respuesta en función de sus asociaciones corporales-sonoro-musicales. Se lleva a cabo con el objeto intermediario (cualquier objeto del setting). Siempre hay un objeto integrador que lidera sobre los demás y los unifica (Benenzon, 2011). 
Efectivamente, se pretende abrir canales de comunicación porque a partir de aquí surge la socialización (Benenzon, 2011). A través de la improvisación musical buscamos:

- Reorganizar las zonas de la personalidad olvidadas o desconocidas de cada usuario/a.

- Fomentar la creatividad, que es el mejor antídoto contra la inercia terapéutica, intentando romper con los prejuicios del "no se puede".

- Impulsar la relajación y producirles un pensamiento positivo, a través del caldeamiento y la catarsis.

- Aplicar el elemento primordial del contexto no-verbal, que es la repetición de las estructuras musicales que aprenden: les gratificará reconocerlas al volver a escucharlas. El canto se acompaña de movimiento, percusión corporal, golpes, instrumentos musicales (pequeña percusión y placas propios del instrumental Orff) y otros.

- Interrelacionar con el cuerpo del musicoterapeuta para provocar la entrada en el paciente e interrelacionar sus movimientos, sus sensaciones y sus energías, individual y colectivamente.

- Expresar con alguna parte del cuerpo, cualquier asociación producida por el ISO en Interacción (un movimiento, un canto, un silbido, una percusión, un grito, un susurro, un murmullo...). Cualquier elemento es válido para crear un instrumento que acompañe y produzca el vínculo.

Mediante la práctica de canciones, patrones rítmicos e improvisaciones seleccionados por el musicoterapeuta (Historia de Vida Musical) se desarrolla la atención, la memoria, la comunicación o la expresión de sentimientos, ya que usuarios/as pueden participar.

Refiriéndose a las improvisaciones, Bruscia (1999) afirma que son inventivas, espontáneas, extemporáneas e ingeniosas. Abundando en esta idea, Herkenrath (2002), considera que la música improvisada ofrece una estrategia para evaluar la percepción y orientación de los pacientes con lesión cerebral grave que presentan un mínimo de acciones o reacciones. Sin embargo, Aldridge y Aldridge (2008, p.185) encuentran que con la improvisación creativa "se anima a los pacientes con depresión a expresar sus emociones, involucrando la cognición y así obtener un acceso inmediato a sus procesos mentales internos". Por su parte, Soria et al. (2011) argumentan que la improvisación supone una serie de efectos ordenados según el modelo de procesamiento de la información, a través de tres componentes: 1) Entrada, en la que participan los órganos de los sentidos; 2) Procesamiento, que involucra el sistema nervioso central; y, 3) Salida, con la participación del sistema muscular y glandular. En efecto, se ha demostrado que la improvisación es "un gran potencial para ser una actividad importante en rehabilitación en personas que han sufrido una lesión cerebral traumática" (Gilbertson y Aldridge, 2008, p.13).

En este programa, a través de la improvisación no-verbal, se persigue como objetivo que afloren el inconsciente, consciente y preconsciente, como preconiza el Modelo y, como novedad, vamos más allá al plantearnos una serie de dimensiones psicológicas derivadas de la Escala de Bienestar Psicológico de Ryff (Autoaceptación, Autonomía, Relaciones Positivas, Dominio del Entorno, Crecimiento Personal, Propósito en la Vida). Se estructuró en bloques de cinco sesiones cada uno, de tal manera que no se altere la libertad de expresión no-verbal del usuario/a para, posteriormente, comprobar si lo planteado tiene validez. Coincidiendo con la finalización de cada bloque se hace una puesta en común de lo vivenciado.

En la fase terapéutica se busca que el musicoterapeuta haga uso de toda su capacidad de comunicarse con el paciente, distinguiendo tres etapas dentro de la sesión, en la línea de Benenzon (2011) y Romero (2012):

1. Caldeamiento o catarsis. Consiste en preparar el "organismo para la acción".

2. Percepción y observación del encuadre no verbal. El musicoterapeuta percibe el ISO del usuario/a e intenta abrir un canal de comunicación.

3. Diálogo sonoro. Una vez establecido el vínculo es cuando se cree que se produce el efecto terapéutico porque lo que se está buscando es una comunicación sonora no-verbal con otra persona.

La intervención de musicoterapia está constituida por un bloque 0 , de adaptación al objeto intermediario del Modelo Benenzon y seis bloques a desarrollar en cinco sesiones de 2 horas de duración: Bloque 1, la Autoaceptación o capacidad de la persona de sentirse satisfecha consigo misma y aceptando sus limitaciones; Bloque 2, la Autonomía o capacidad de independencia y autodeterminación en sus decisiones; Bloque 3, las Relaciones positivas o capacidad de la persona para mantener relaciones de confianza estables y de intimidad con los demás; Bloque 4, el Dominio del entorno o control de las responsabilidades y decisiones tomadas en el día a día; Bloque 5, el Crecimiento personal o autorrealización; y, Bloque 6, el Propósito de vida. El modelo de sesiones aparece reflejado en la Tabla 1. Se especifican las actividades programadas que se realizan a través de las improvisaciones no-verbales: rítmicas y melódicas, efectuadas con todos los instrumentos del setting, (espacio, objetos y/o instrumentos dispuestos en la sala utilizados para la comunicación no-verbal) con partes del cuerpo, con la voz, individualmente o con la colaboración de algún compañero o musicoterapeuta. A veces afloran espontáneamente patrones rítmicos o melódicos, e incluso canciones populares y fragmentos evocadores de músicas conocidas que acompañan con el objeto intermediario o con percusión corporal. A través de ellas van aflorando los vínculos y se ponen de manifiesto los diferentes ISOs. 
Se ha seguido un esquema de análisis cualitativo con los datos recogidos a lo largo de las 35 sesiones: sobre la mejoría observada, la utilidad de la intervención de musicoterapia, la posterior reflexión sobre lo trabajado y si es apropiada para aplicarla a este tipo de usuarios/as y, finalmente, su grado de satisfacción.

Tabla 1. Modelo de sesión por bloques: Bloques 0 y 1

\begin{tabular}{|c|c|c|c|c|c|}
\hline \multicolumn{6}{|c|}{ RESUMEN DEL PROGRAMA DE INTERVENCIÓN POR BLOQUES } \\
\hline BLOQUES & OBJETIVOS & CONTENIDOS & ACTIVIDADES & $\begin{array}{l}\text { SESIO- } \\
\text { NES }\end{array}$ & $\begin{array}{l}\text { DURA- } \\
\text { CIÓN }\end{array}$ \\
\hline \multirow{5}{*}{$\begin{array}{l}\text { BLOQUE 0: } \\
\text { ADAPTACIÓN } \\
\text { AL OBJETO IN- } \\
\text { TERMEDIARIO. } \\
\text { "APRENDEMOS } \\
\text { A COMUNICAR- } \\
\text { NOS CON LEN- } \\
\text { GUAJE NO-VER- } \\
\text { BAL" }\end{array}$} & $\begin{array}{l}\text { 01. Presentar el } \\
\text { setting. } \\
\text { 02. Dar a conocer } \\
\text { las sesiones. } \\
\text { 03. Descubrir su } \\
\text { capacidad motora. }\end{array}$ & $\begin{array}{l}\text { El setting: es- } \\
\text { pacio, objetos } \\
\text { y/o instrumentos } \\
\text { de la sala que } \\
\text { pueden ser uti- } \\
\text { lizados para la } \\
\text { comunicación } \\
\text { no-verbal. }\end{array}$ & $\begin{array}{l}\text { Presentación de los instrumentos del } \\
\text { setting: } \\
\text {-El musicoterapeuta (MT), realiza es- } \\
\text { quemas rítmicos y melódicos con cada } \\
\text { instrumento. } \\
\text {-Práctica libre por parte de usuarios y } \\
\text { usuarias (US). } \\
\text {-Sin melodías regladas ni partituras. } \\
\text {-Afloramiento espontáneo, a veces, de } \\
\text { músicas conocidas. } \\
\text {-Ecos, variaciones, diálogos sonoros } \\
\text { tras propuestas del MT. }\end{array}$ & $1^{\mathrm{a}}$ & 2 horas \\
\hline & $\begin{array}{l}04 . \text { Descubrir qué } \\
\text { instrumentos les } \\
\text { atraen. }\end{array}$ & $\begin{array}{l}\text { Instrumentos que } \\
\text { se van a utilizar } \\
\text { y mesa a ubicar. }\end{array}$ & $\begin{array}{l}\text {-Los US realizan patrones rítmicos con } \\
\text { instrumentos afines. } \\
\text {-Comunicación a través de sonidos, } \\
\text { ruidos y movimientos corporales. } \\
\text {-Improvisaciones libres o imitando al } \\
\text { MT o a cualquier compañero/a. }\end{array}$ & $2^{\mathrm{a}}$ & 2 horas \\
\hline & $\begin{array}{l}\text { 05. Adquirir habili- } \\
\text { dades para adaptar- } \\
\text { se al grupo. }\end{array}$ & $\begin{array}{l}\text { Experimentar } \\
\text { distintos timbres } \\
\text { e intensidades } \\
\text { sonoras. }\end{array}$ & $\begin{array}{l}\text { Búsqueda del verdadero arquetipo } \\
\text { corpóreo-sonoro-musical: } \\
\text {-Los US “experimentarán” sonoridades } \\
\text { e intensidades con los instrumentos del } \\
\text { setting. }\end{array}$ & $3^{\mathrm{a}}$ & 2 horas \\
\hline & $\begin{array}{l}06 . \text { Conocer el tipo } \\
\text { de ayuda que nece- } \\
\text { sita el usuario/a en } \\
\text { el uso del instru- } \\
\text { mento. }\end{array}$ & $\begin{array}{l}\text { La comunicación } \\
\text { no-verbal. }\end{array}$ & $\begin{array}{l}\text { Improvisaciones no-verbales con el ob- } \\
\text { jeto intermediario para aflorar el ISO: } \\
\text {-Se invitará a los US a expresar sus } \\
\text { sentimientos a través de improvisacio- } \\
\text { nes libres con el instrumento escogido } \\
\text { (objeto intermediario). } \\
\text {-Se observarán los ritmos predominan- } \\
\text { tes, para descubrir su Historia de Vida } \\
\text { sonoro-musical. }\end{array}$ & $4^{\mathrm{a}}$ & 2 horas \\
\hline & $\begin{array}{l}\text { 07. Conocer que la } \\
\text { MTP es un mundo } \\
\text { sonoro-no-verbal } \\
\text { de comunicación. } \\
\text { 08. Mostrar qué es } \\
\text { la comunicación } \\
\text { no-verbal. }\end{array}$ & Los ISOs. & $\begin{array}{l}\text { Descubrimiento ISO Universal y Ges- } \\
\text { táltico: } \\
\text {-ISO Universal: energías producidas } \\
\text { por nuestro cuerpo: sonido y ritmo } \\
\text { cardiaco; los sonidos de la naturaleza } \\
\text { (viento y agua); estructuras como melo- } \\
\text { días infantiles o canciones de cuna. } \\
\text {-ISO Gestáltico: reconocimiento de la } \\
\text { vida musical del usuario/a desde sus } \\
\text { comienzos, inferida a través de sus } \\
\text { improvisaciones no-verbales. } \\
\text {-Diálogos sonoros a partir de improvi- } \\
\text { saciones para abrir canales de comuni- } \\
\text { cación con el MT o US. } \\
\text {-Reflexión final sobre la adaptación a } \\
\text { los instrumentos intermediarios. }\end{array}$ & $5^{\mathrm{a}}$ & 3 horas \\
\hline
\end{tabular}




\begin{tabular}{|c|c|c|c|c|c|}
\hline \multirow{5}{*}{$\begin{array}{l}\text { BLOQUE 1: } \\
\text { AUTOACEPTA- } \\
\text { CIÓN. } \\
\text { "SOMOS POSI- } \\
\text { TIVOS" }\end{array}$} & $\begin{array}{l}\text { A1. Reconocerse } \\
\text { como persona vá- } \\
\text { lida. }\end{array}$ & $\begin{array}{l}\text { Las emociones } \\
\text { negativas. Su } \\
\text { influencia sobre } \\
\text { nuestra vida. }\end{array}$ & $\begin{array}{l}\text { Creatividad a través del movimiento y } \\
\text { del gesto: } \\
\text {-Consigna al inicio de cada sesión. } \\
\text {-Improvisaciones pensando en la autoa- } \\
\text { ceptación. } \\
\text {-El MT interpreta ritmos alegres con } \\
\text { gesto optimista y tomando iniciativas } \\
\text { no verbales. } \\
\text {-Asociaciones (ISO en Interacción) } \\
\text { usando partes del cuerpo, movimientos, } \\
\text { cantos, silbidos, chasquidos de dedos, } \\
\text { percusión de manos o pies, gritos, } \\
\text { murmullos y ritmos moviendo silla de } \\
\text { ruedas. }\end{array}$ & $6^{\mathrm{a}}$ & 2 horas \\
\hline & $\begin{array}{l}\text { A2. Desarrollar una } \\
\text { relación terapéutica } \\
\text { no-verbal. }\end{array}$ & $\begin{array}{l}\text { Miedo, ansiedad, } \\
\text { tristeza, depre- } \\
\text { sión, ira. }\end{array}$ & $\begin{array}{l}\text { ISO en Interacción: usar alguna parte } \\
\text { del cuerpo, como instrumento para } \\
\text { relacionarse: } \\
\text {-Apertura del canal de comunicación a } \\
\text { través del cuerpo, cantando o acompa- } \\
\text { ñando ritmos improvisados por el MT. } \\
\text {-Tararear, cantar estribillos de cancio- } \\
\text { nes populares evocadas (se entiende } \\
\text { como secuencia dentro del proceso } \\
\text { terapéutico en el que el ritmo libre se } \\
\text { adapta a sus posibilidades). }\end{array}$ & $7^{\mathrm{a}}$ & 2 horas \\
\hline & $\begin{array}{l}\text { A3. Reorganizar las } \\
\text { zonas de la perso- } \\
\text { nalidad olvidada } \\
\text { del usuario/a. }\end{array}$ & $\begin{array}{l}\text { Los estados } \\
\text { emocionales que } \\
\text { afectan nega- } \\
\text { tivamente a la } \\
\text { calidad de vida } \\
\text { como factor de } \\
\text { riesgo. }\end{array}$ & $\begin{array}{l}\text { Fortalecimiento del holding musicote- } \\
\text { rapéutico entre MT y US: } \\
\text {-Ritualización de secuencias. } \\
\text {-Repetición de piezas musicales de } \\
\text { sesiones anteriores. } \\
\text {-Acompañamientos rítmicos. }\end{array}$ & $8^{a}$ & 2 horas \\
\hline & $\begin{array}{l}\text { A4. Ayudar a pro- } \\
\text { cesar los recuerdos } \\
\text { emocionales nega- } \\
\text { tivos. }\end{array}$ & $\begin{array}{l}\text { La importancia } \\
\text { de la autoacep- } \\
\text { tación. }\end{array}$ & $\begin{array}{l}\text {-Mentalizados en la consigna, los US } \\
\text { improvisarán desinhibiéndose e inte- } \\
\text { ractuando poco a poco, a través de los } \\
\text { objetos intermediarios escogidos. } \\
\text {-Se ritualizarán secuencias en las im- } \\
\text { provisaciones. } \\
\text {-Desarrollo del lenguaje no-verbal. } \\
\text {-Búsqueda de la comunicación de emo- } \\
\text { ciones con gestos, mímicas y expresio- } \\
\text { nes sonoras vocales. }\end{array}$ & $9^{a}$ & 2 horas \\
\hline & $\begin{array}{l}\text { A5. Evocar los } \\
\text { recuerdos. } \\
\text { A6. Llegar a cono- } \\
\text { cer la Autoacepta- } \\
\text { ción. }\end{array}$ & $\begin{array}{l}\text { Los recuerdos. } \\
\text { La autoacepta- } \\
\text { ción. }\end{array}$ & $\begin{array}{l}\text { Historia de Vida sonoro musical y de- } \\
\text { bate: } \\
\text {-Evocación de recuerdos mediante el } \\
\text { sonido y el gesto facial-corporal. } \\
\text {-Afianzamiento del vínculo. } \\
\text {-Debate reflexionando sobre la autoa- } \\
\text { ceptación, cómo ser más positivos, el } \\
\text { orgullo, el entusiasmo, la seguridad } \\
\text { y las dificultades de la comunicación } \\
\text { no-verbal de estos sentimientos. }\end{array}$ & $10^{\mathrm{a}}$ & 3 horas \\
\hline
\end{tabular}

Fuente: Elaboración propia.

El setting se instaló en dos salas diferentes de la Institución. La sala de usos múltiples, aislada acústicamente para favorecer la vibración con sus paredes pintadas de color blanco y sin decoración alguna, posee unas dimensiones de 20 x 10 metros, suficientes para permitir la libertad de movimiento. Una segunda sala reúne las mismas condiciones, pero las dimensiones son de 4 x 8 metros. En ambas, los objetos intermediarios se colocan sobre una mesa para facilitar su uso a los usuarios/as que están en sillas de ruedas. 


\section{Resultados}

Para el tratamiento de la información se ha seguido a Denzin (1970), que indica que la triangulación en el análisis es la combinación de dos o más teorías, de dos o más fuentes de datos, de dos o más observadores expertos, de dos o más métodos de investigación (cualitativo y cuantitativo) en el estudio de un fenómeno singular.

Se ha triangulado el resultado de las observaciones recogidas a lo largo de las sesiones y se han sistematizado y transformado en frecuencias. Igualmente, con el propósito de su validación, se han aplicado diferentes instrumentos a las mismas dimensiones trabajadas y comparado los resultados de los datos obtenidos, permitiendo separar lo importante de lo superfluo. Finalmente, se lleva a cabo una síntesis de los datos que se han recopilado para realizar un estudio cuantitativo, obteniendo una serie de conclusiones. Al tratarse de un diseño cuasiexperimental no se puede atribuir la mejora únicamente a esta intervención, ya que hay conciencia de la influencia de variables extrañas que no se pueden controlar.

\subsection{Valoración del Bienestar Psicológico}

En este estudio se ha supuesto que habría una diferencia significativa entre los constructos medidos con la escala del Bienestar Psicológico, antes de la intervención de musicoterapia (pre-intervención) y después de someterse a la intervención (post-intervención), que les afectaría positivamente. Con $\mathrm{H}_{1}$ suponemos que hay una diferencia significativa entre medidas de estos constructos, antes y después de la intervención de musicoterapia. Con $\mathrm{H}_{0}$ suponemos que no hay una diferencia significativa entre medidas de estos constructos, antes y después de la intervención.

Como se puede observar en la Tabla 2, los resultados arrojan una diferencia significativa entre las medias de los constructos, a favor de la intervención, en todas las variables consideradas, que explican que la musicoterapia puede mejorar la visión de los usuarios/as y usuarias sobre su calidad de vida y salud percibida.

Tabla 2. Prueba de medias por variables. Bienestar Psicológico

\begin{tabular}{|c|c|c|c|c|c|c|c|c|}
\hline \multirow{2}{*}{\multicolumn{2}{|c|}{ Variables }} & \multirow{2}{*}{ Media } & \multirow{2}{*}{ DT } & \multirow{2}{*}{$\begin{array}{c}\mathbf{t}(\mathbf{p}) \\
\text { Coeficiente }\end{array}$} & \multicolumn{2}{|c|}{ Asimetría } & \multicolumn{2}{|c|}{ Curtosis } \\
\hline & & & & & Coeficiente & Error & Coeficiente & Error \\
\hline \multirow{2}{*}{ Autoaceptación } & Pre-test & 3,78 & 0,94 & \multirow{2}{*}{$\begin{array}{c}-3,798 \\
0,004\end{array}$} & $-0,28$ & 0,68 & $-1,69$ & 1,334 \\
\hline & Pos-test & 4,90 & 0,25 & & 0,12 & 0,69 & $-0,36$ & 1,334 \\
\hline \multirow{2}{*}{ Autonomía } & Pre-test & 3,75 & 0,46 & \multirow{2}{*}{$\begin{array}{c}-2,261 \\
0,050\end{array}$} & 1,17 & 0,69 & 1,53 & 1,334 \\
\hline & Pos-test & 4,35 & 0,56 & & 0,14 & 0,69 & $-0,09$ & 1,334 \\
\hline \multirow{2}{*}{ Relaciones Positivas } & Pre-test & 3,77 & 1,11 & \multirow{2}{*}{$\begin{array}{c}-3,383 \\
0,008\end{array}$} & $-0,87$ & 0,69 & $-0,29$ & 1,334 \\
\hline & Pos-test & 4,90 & 0,25 & & $-1,35$ & 0,69 & 2,08 & 1,334 \\
\hline \multirow{2}{*}{ Dominio del entorno } & Pre-test- & 3,33 & 0,67 & \multirow{2}{*}{$\begin{array}{c}-5,298 \\
0,000\end{array}$} & 0,10 & 0,69 & $-1,58$ & 1,334 \\
\hline & Pos-test & 4,70 & 0,52 & & 0,29 & 0,69 & $-1,39$ & 1,334 \\
\hline \multirow{2}{*}{$\begin{array}{c}\text { Crecimiento } \\
\text { Personal }\end{array}$} & Pre-test & 3,80 & 0,64 & \multirow{2}{*}{$\begin{array}{c}-3,394 \\
0,008\end{array}$} & $-0,25$ & 0,69 & $-0,93$ & 1,334 \\
\hline & Pos-test & 4,70 & 0,49 & & 0,19 & 0,69 & $-0,92$ & 1,334 \\
\hline \multirow{2}{*}{ Propósito en la vida } & Pre-test & 3,35 & 0,82 & \multirow{2}{*}{$\begin{array}{c}-3,446 \\
0,007\end{array}$} & 0,07 & 0,69 & $-1,51$ & 1,334 \\
\hline & Pos-test & 4,42 & 0,52 & & 0,56 & 0,69 & 2,17 & 1,334 \\
\hline
\end{tabular}

El nivel de significación es $(\mathrm{p}=0,05)$.

Fuente: Elaboración propia con paquete estadístico SPSS.

En la Tabla 2 se observa que los resultados arrojan una diferencia significativa entre las medias de los constructos, a favor de la intervención musicoterapéutica: en las variables autoaceptación ( $\mathrm{t}=-3,798, \mathrm{p}=0,004)$, relaciones positivas $(-3,383, p=0,008)$, dominio del entorno $(-5,298, p=0,000)$, crecimiento personal $(-3,394, p=0,008)$ y propósito en la vida $(3-3,446, p=0,007)$. Es la variable autonomía sobre la que menos efectos tiene la intervención, a pesar de que la media del postest es más elevada, siendo la diferencia a nivel estadístico no significativa en el nivel considerado $(\mathrm{t}=-2,261, \mathrm{p}=0,05)$. Los coeficientes de asimetría $(<3,00)$ y curtosis $(<8,00)$, dan a entender que existe normalidad univariada de los datos obtenidos (Theode, 2002). Estos resultados explican que la musicoterapia puede mejorar la visión de usuarios/as sobre su calidad de vida y salud percibida. 
Tabla 3. Prueba de muestras emparejadas por sexo. Bienestar Psicológico

\begin{tabular}{|c|c|c|c|c|c|c|c|}
\hline \multicolumn{3}{|c|}{ Variables } & Sexo & Media & DT & $\begin{array}{l}\text { Media } \\
\text { de error }\end{array}$ & Grupo favorable \\
\hline \multirow{4}{*}{ Par 1} & \multirow{4}{*}{ Autoaceptación } & \multirow{2}{*}{ Pre-test } & Hombre & 3,80 & 0,97 & 0,36 & - \\
\hline & & & Mujer & 3,72 & 1,07 & 0,61 & - \\
\hline & & \multirow{2}{*}{ Pos-test } & Hombre & 4,88 & 0,26 & 0,10 & - \\
\hline & & & Mujer & 4,94 & 0,25 & 0,14 & Mujer \\
\hline \multirow{4}{*}{ Par 2} & \multirow{4}{*}{ Autonomía } & \multirow{2}{*}{ Pre-test } & Hombre & 3,67 & 0,32 & 0,12 & - \\
\hline & & & Mujer & 3,91 & 0,76 & 0,44 & Mujer \\
\hline & & \multirow{2}{*}{ Pos-test } & Hombre & 4,19 & 0,52 & 0,19 & - \\
\hline & & & Mujer & 4,70 & 0,57 & 0,33 & Mujer \\
\hline \multirow{4}{*}{ Par 3} & \multirow{4}{*}{ Relaciones positivas } & \multirow{2}{*}{ Pre-test } & Hombre & 3,64 & 1,26 & 0,47 & - \\
\hline & & & Mujer & 4,05 & 0,78 & 0,45 & Mujer \\
\hline & & \multirow{2}{*}{ Pos-test } & Hombre & 4,90 & 0,28 & 0,10 & - \\
\hline & & & Mujer & 4,88 & 0,19 & 0,11 & - \\
\hline \multirow{4}{*}{ Par 4} & \multirow{4}{*}{ Dominio del entorno } & \multirow{2}{*}{ Pre-test } & Hombre & 3,47 & 0,73 & 0,27 & - \\
\hline & & & Mujer & 3,00 & 0,44 & 0,25 & - \\
\hline & & \multirow{2}{*}{ Pos-test } & Hombre & 4,78 & 0,50 & 0,19 & - \\
\hline & & & Mujer & 4,50 & 0,60 & 0,34 & - \\
\hline \multirow{4}{*}{ Par 5} & \multirow{4}{*}{ Crecimiento personal } & \multirow{2}{*}{ Pre-test } & Hombre & 3,91 & 0,66 & 0,25 & - \\
\hline & & & Mujer & 3,52 & 0,59 & 0,34 & - \\
\hline & & \multirow{2}{*}{ Pos-test } & Hombre & 4,71 & 0,54 & 0,20 & - \\
\hline & & & Mujer & 4,66 & 0,45 & 0,26 & - \\
\hline \multirow{4}{*}{ Par 6} & \multirow{4}{*}{ Propósito de vida } & \multirow{2}{*}{ Pre-test } & Hombre & 3,38 & 0,92 & 0,34 & - \\
\hline & & & Mujer & 3,27 & 067 & 0,38 & - \\
\hline & & \multirow{2}{*}{ Pos-test } & Hombre & 4,28 & 0,42 & 0,16 & - \\
\hline & & & Mujer & 4,72 & 0,67 & 0,38 & Mujer \\
\hline
\end{tabular}

El nivel de significación es $(\mathrm{p}=0,05)$.

Fuente: Elaboración propia con paquete estadístico SPSS.

Se observa en la Tabla 3 una diferencia significativa entre las medias de los constructos, a favor de la intervención musicoterapéutica, en todas las variables: Autoaceptación (3,80 del pretest, frente a 4,88 del postest respecto a los hombres; y 3,72 del pre-test, frente a 4,94 del post-test respecto a las mujeres). Autonomía (3,67 del pretest, frente a 4,19 del postest en los hombres; y 3,91 del pretest, frente a 4,70 del postest en las mujeres). Relaciones positivas (3,64 del pretest, frente a 4,90 del postest en los hombres; y 4,05 del pretest, frente a 4.88 del postest en las mujeres). Dominio del entorno (3,47 del pretest, frente a 4,78 del postest en los hombres; y 3,00 del pretest, frente a 4,50 del postest en las mujeres). Crecimiento personal (3,91 del pretest, frente a 4,71 del postest en los hombres y 3,52 del pretest, frente a 4.66 del postest en las mujeres). Y propósito en la vida (3,38 del pretest, frente a 4,28 del postest en los hombres; y 3,27 del pretest, frente a 4,72 del postest en las mujeres). Resultados que demuestran que las mujeres obtienen mejores resultados en el postest en las variables autoaceptación (4,88 del hombre, frente a 4,94 de la mujer), autonomía (4,19 del hombre, frente a 4,70 de la mujer), y propósito de vida (4,28 del hombre, frente a 4,72 de la mujer).

\subsection{Valoración de la efectividad de la intervención}

Dentro de las sesiones de musicoterapia se propició la reflexión sobre cada una de las variables trabajadas en referencia al bienestar psicológico, sobre la base de que las emociones, las experiencias positivas, el optimismo, la dedicación activa e intrínsecamente motivada, son elementos que pueden mejorar la salud de estos usuarios/as, en la línea de "identificar y utilizar lo que uno hace bien puede ser una manera eficaz de abordar y resolver problemas psicológicos al aprovechar las fortalezas y las cualidades personales" (Park et al., 2013, p. 12).

El bloque 0, al ser de introducción y adaptación a los objetos intermediarios, no se ha estandarizado. Los participantes, tras estas sesiones manifestaron su satisfacción con frases como "Yo ya sé cómo se toca" o "Este es el que más me gusta". Uno de los usuarios/as aportó un pequeño teclado al setting y, aunque este tipo de instrumentos electrónicos no se aconsejan en el Modelo Benenzon, por considerar que en la comunicación no-verbal pierden fuerza frente a los instrumentos llamados analógicos o naturales, se admitió como deferencia. 


\section{Desarrollo de las sesiones:}

a) Se ha trabajado la Autoaceptación, utilizando la capacidad de ser positivos, reconociendo lo que valen y que tienen capacidad de querer, de ser queridos y respetados "a pesar de no ser perfectos". Se les ha enseñado a ser positivos, coincidiendo con Park et al. (2013), dado que es muy importante la actitud que una persona tenga ante una enfermedad incapacitante. Con la intervención se ha buscado que reflexionen ante la adversidad y muestren una actitud más positiva. Al finalizar cada uno de los bloques, se ha llevado a cabo una serie de preguntas sobre la dimensión trabajada, con el fin de comprobar el grado de efectividad de la intervención musicoterapéutica. Todo ello, con las limitaciones de comunicación verbal y reflexión inherentes al tipo de situación en la que se encuentran los participantes de la intervención, a los que se ha tenido que ayudar a expresarse, cuando no a interpretar lo que han querido decir en cada momento, dándose la situación de que cuando uno expresaba una idea, otros asentían. No obstante, la experiencia ha sido positiva por cuanto se ha tratado de dar visibilidad a estas personas.

Teniendo en cuenta que estos usuarios/as viven como residentes en una Institución y que, a corto plazo, no tienen esperanzas de salir de ella, de estas respuestas se desprende que la mayoría de los participantes navegan en un mar de confusiones porque, de un lado está la realidad que viven en su día a día, y, de otro, las expectativas que puedan tener por vivir de otra manera. En algunos se intuye cierta resignación, con respuestas como "estoy bien" o "soy así". "me gustaría estar en mi casa". En otros se observa más optimismo y ganas de vivir afrontando su situación, manifestados en respuestas como "me sentiría mejor", "estaría mejor", "me da igual", "sí, estoy orgulloso". Respuestas que han sido estandarizadas en la Tabla 5 del Anexo 2 para unificarlas y transformarlas en frecuencias.

b) Se ha favorecido la Autonomía personal, usando las fortalezas más características de esta dimensión (autoafirmación, responsabilidad, despreocupación de lo que los demás piensan o dicen de ti, imponiendo responsablemente tu voluntad). Coincidiendo con Park et al (2013), cuando señala que la confianza aumenta al aprender a utilizarla para superar sus debilidades o fortalezas menos desarrolladas.

Respecto a la autonomía física, se observa que todos tienen asumido que su vida depende de un cuidador y, por tanto, tienen una cierta resignación, con respuestas como "yo no quiero «que se enfaden»" o "no me gusta". En cuanto a la autonomía en sus decisiones, hay cierta disparidad dependiendo de su carácter, observada a través de respuestas como: "no me entienden", "no me echan cuenta", "no me hacen caso" o "es por mi bien".

Como se puede ver, la mayoría supeditan sus decisiones más importantes a la opinión de las personas que les rodean. Todas las respuestas han sido estandarizadas y representadas en la Tabla 6 del Anexo 2 para unificarlas y transformarlas en frecuencias.

c) Se han fomentado las Relaciones positivas, coincidiendo con Park et al (2013, p. 15) cuando afirman que "las relaciones buenas con otras personas (amigos, familiares y compañeros de trabajo) son el factor que contribuye de manera más importante a la buena vida psicológica".

Esta dimensión es la que más se deriva del vínculo entre musicoterapeuta y paciente y con el resto del grupo. En ella, se observa si los pacientes han descubierto su ISO y han conectado con el terapeuta. En general, se constata que les ha resultado difícil la comunicación sonoro-musical, pero, no obstante, han llevado a cabo diálogos sonoros, improvisaciones colectivas, escucha activa, etc., que les han acercado a sus compañeros y les han abierto una ventana a la comunicación y a unas relaciones más fluidas.

Respecto a sus sentimientos sobre la situación de comunicación a través del lenguaje no-verbal, han tenido respuestas en la línea de "me he sentido raro", "me ha gustado" o "es difícil". En relación al fomento de la amistad y/o si tus amigos te ayudan, se han obtenido respuestas como: "tengo más amigos", "sí, me ayudan "o "no me ayudan". Respuestas que han sido estandarizadas y representadas en la Tabla 7 del Anexo 2.

d) Se ha trabajado el "Dominio del Entorno", entendido como capacidad para aceptar las responsabilidades y decisiones tomadas en el día a día, de dirigir su propia vida, de construir un modo de vida acorde con su forma de ser, de hacer frente a las demandas diarias o de relajarse y hacer lo posible para ser feliz.

De nuevo nos encontramos con unas respuestas que están mediatizadas por su situación física, que les recuerda y convierte en personas con dependencia. Su deseo de ser independientes choca de manera frontal con la realidad y de dichas respuestas se desprende una resignación, con respuestas en la línea de "no hago muchas «cosas»", "yo lo hago bien", "a mí me ayudan", "me tienen que ayudar" o "dependo de otros".

No obstante, con nuestra intervención lo hemos querido paliar, en la medida de lo posible, y durante el transcurso de las sesiones hemos observado que se han evadido y han disfrutado de lo que estaban haciendo. Prueba de ello es que siempre que sus dificultades fisiológicas o médicas se lo han permitido, han asistido con gusto a las sesiones. Las respuestas se muestran en la Tabla 8 del Anexo 2, unificadas y transformadas en frecuencias.

e) Se ha favorecido el Crecimiento personal, y se asume con Park et al. (2013) que se fortalece el carácter, cuando afirman que en las historias de traumas (como los accidentes con peligro para la vida, asaltos, enfermedades y desastres naturales) encontraron aumentos en fortalezas como la amabilidad, el amor, la curiosidad, la creatividad, el amor 
por el aprendizaje, la apreciación de la belleza, la gratitud, el entusiasmo, la valentía, la honestidad, la perseverancia y la religiosidad/espiritualidad (Park et al., 2013, p. 14).

Se habla de esperanzas de mejora de vida y se observa que las menos son negativas o de resignación, materializadas en expresiones como "sí, tengo miedo", "no lo sé". Sin embargo, no se puede obviar que otras han sido de optimismo y fe en el futuro, cuando han respondido con "no tengo miedo", "yo me conozco", "mucho mejor" o "contento". No obstante, en el transcurso de las sesiones se ha podido observar que con esta intervención se ha contribuido a que cambien su actitud, rompiendo la monotonía de sus días. Las respuestas han sido estandarizadas y representadas en la Tabla 9 del Anexo 2.

f) Se ha fomentado el Propósito de Vida. Se afirma en consonancia con Park et al. (2013) que las personas con un sentido de propósito y significado tienen mayor satisfacción con la vida, un afecto más positivo, niveles más altos de optimismo y mejor autoestima y, además, tienen menos problemas psicológicos (Park et al., 2013, p. 15). Se observa que la mayoría no tiene ningún plan para el futuro, que viven el día a día y que este tema no les preocupa demasiado, materializado en respuestas como "quiero estar bien", "no tengo planes" "que me curen", "ponerme bien", "siempre estoy alegre". Respuestas que han sido estandarizadas y representadas en la Tabla 10 del Anexo 2.

A lo largo de la intervención, y en consonancia con Park (2013, p. 17), se ha procurado mantener un clima de tranquilidad y buen humor, fomentando la amistad. Al finalizar cada una de las sesiones hemos aplicado la técnica del Saboreo, haciéndoles recordar los momentos más positivos que han vivido, como residentes de la Institución. Efectivamente, se han visualizado fotografías de eventos y fiestas, recordado y contado anécdotas sucedidas, momento que les ha resultado placentero. También se ha pedido a los usuarios/as que compartan las cosas buenas que les han ocurrido durante la sesión y razonen su por qué, con la finalidad de que practiquen y sean más conscientes de lo que han hecho para que les sirva de refuerzo positivo.

\section{Discusión y conclusiones}

Atendiendo al objetivo planteado y a los hallazgos obtenidos en el análisis de los resultados, se puede afirmar que los participantes en esta investigación describen una mejoría general en su estado anímico. Se evidencian cambios significativos en la dinámica relacional del grupo, en la respuesta de participación individual en la que muestran gran interés por la realización de las actividades, en la mejor predisposición a la hora de afrontar su situación y en la mayor alegría y desenvoltura a la hora de afrontar las sesiones. En esta misma línea, se coincide con Martí et al. (2015b) que afirman que la musicoterapia reduce los efectos de los estímulos nocivos mientras que eleva el estado anímico y los sentimientos de confort y sensación de control.

Se aprecia, comparando los resultados del pretest y pos-test y la valoración del grupo sobre la efectividad de la intervención, que los participantes tienen una mejor autoaceptación, unas relaciones más positivas con sus compañeros y todos los que les rodean, un mayor crecimiento personal y un mejor propósito de vida. No tanto en autonomía, cuyo resultado no ha variado de manera significativa, aunque la valoración del grupo evidencia una mejora global en el bienestar psicológico y en su calidad de vida percibida. Resultados en consonancia con Martí et al. (2015b) afirmando que la musicoterapia puede ayudar a mejorar el estado de ánimo y la calidad de vida de los participantes.

A lo largo de la intervención, con la observación y recogida de datos, se ha podido comprobar una mayor participación femenina, tanto en las actividades de improvisación y la repetición de patrones rítmicos de temas conocidos, como de canto de canciones conocidas. Efectivamente, constatado a través de la aplicación (postest) de la Escala de Beneficios Psicológicos de Ryff (1989a), sometida a tratamiento estadístico descriptivo de muestras emparejadas por sexo, que recoge las dimensiones estudiadas: el sexo, la media de puntuación, la desviación estándar y la media de error. También se ha podido observar que los resultados en las variables autoaceptación, autonomía, relaciones positivas y propósito de vida, favorecen al grupo de mujeres. Resultados que difieren de los obtenidos por Helvik et al. (2006) que encuentran que los hombres con discapacidad muestran niveles más altos que las mujeres en todas las dimensiones del bienestar.

La comunicación no-verbal a través de las improvisaciones ha permitido a los participantes comunicarse con otros del grupo que sufren su misma situación y para afrontar de una forma más positiva los efectos derivados de ésta, aumentando sus relaciones sociales. Beneficios en consonancia con lo apuntado por Särkämö et al. (2014) que sostienen que a través de una intervención musicoterapéutica se puede ayudar a mantener la salud física y mental.

Se ha comprobado que el descubrimiento de los ISOs por parte de los usuarios/as y del musicoterapeuta no es una tarea fácil. Llegar al ISO en Interacción, haciéndolos actuar, interesarlos y motivarlos para que sus improvisaciones tuvieran una intención, ha sido laborioso. Sin embargo, se consiguió que se desinhibieran y participaran activamente a lo largo de todas las sesiones y se produjera un vínculo (relación), tanto entre musicoterapeuta y usuarios/as, como entre el grupo. Acudieron a las mismas con alegría y expresaron sin problemas sus emociones y creatividad. Se olvidaron, al menos temporalmente, de sus ansiedades, miedos, aprensiones y angustias e interactuaron con total normalidad con el musicoterapeuta. Resultados en consonancia con lo apuntado por Benenzon (2011) que, en su investigación con enfermos de Alzhéimer, trabaja en la búsqueda de los ISOs porque estimula y se asocia con los afectos y emociones del paciente, que necesita ser escuchado, atendido y acogido para que se produzca el vínculo. 
La musicoterapia, implementada en innumerables contextos por equipos interdisciplinares, demuestra su eficacia como opción no-farmacológica, aunque por el tipo de diseño, el grado de certeza sobre la mejora atribuida a esta intervención no puede ser alto, por no haberse controlado las posibles variables extrañas y porque al usar una muestra reducida no puede hacerse extensible a toda la población.

Continuar investigando en este campo y poner en práctica sus avances puede contribuir de modo significativo a lograr este objetivo, en la línea de lo apuntado por Gold et al. (2007) que concluyen que la musicoterapia puede ayudar a los niños con trastorno de espectro autista a mejorar sus habilidades comunicativas, coincidiendo con Calleja et al. (2016), que encuentran que es una práctica prometedora.

Cabe considerar que los trabajos empíricos sobre este tema son escasos y se necesita seguir investigando, así como sus efectos en la práctica clínica típica. Como ya apuntaran Daykin y Bunt (2015), se destaca la necesidad de nuevas investigaciones sobre las formas en que la musicoterapia puede ayudar en el tratamiento, la rehabilitación y la calidad de vida en una amplia gama de configuraciones.

\section{Referencias bibliográficas}

Aalbers, S., Spreen, M., Bosveld-van Haandel, L. \& Bogaerts, S. (2017). Evaluation of client progress in music therapy: an illustration of an N-of-1 design in individual short-term improvisational music therapy with clients with depression. Nordic Journal of Music Therapy, 26(3), 256-271. http://doi.org/10.1080/08098131.2016.1205649

Abello, R., Amaris, M., Blanco, A., Madariaga, C., Díaz, D. y Arciniégas, T (2008). Bienestar, autoestima, depresión y anomia en personas que no han sido víctimas de violencia política y social. Investigación \& desarrollo, 16(2), 214-231. https://www. redalyc.org/articulo.oa?id=26816201

Aldridge, G. \& Aldridge, D. (2008). Melody in Music Therapy. A Therapeutic Narrative Analysis. London and Philadelphia: Jessica Kingsley Publishers.

Alfaro, J., Casas, F. y López, V. (2015). Bienestar en la infancia y adolescencia. Psicoperspectivas, 14(1), 1-5. https://scielo. conicyt.cl/pdf/psicop/v14n1/art01.pdf

American Music Therapy Association (2014). Music Therapy and Military Populations. Silver Springs (MD): American Music Therapy Association. http://www.musictherapy.org/assets/1/7/MusicTherapyMilitaryPops_2014.pdf

Bascones, L. M., Quezada, M. Y., Fernández, M., López, P. y Tejero, M. (2005). Daño cerebral sobrevenido en España: un acercamiento epidemiológico y socio-sanitario. Madrid: Oficina del Defensor del Pueblo. http://www.infocop.es/pdf/Informe-sobre-daño-cerebral-sobrevenido-en-España.pdf

Benedito, M. C. (2010). Reflexiones en torno a la utilidad de la música en la terapia psicológica con adolescentes. Revista Española de Pediatría Clínica e Investigación, 66(2), 136-140. https://www.seinap.es/wp-content/uploads/Revista-de-Pediatria/2010/REP\%2066-2.pdf\#page=56

Benenzon, R. (2011). Musicoterapia: de la teoría a la práctica. Nueva edición ampliada. (Psicología Psiquiatría Psicoterapia) (Spanish Edition). Edición con formato Kindle. Editorial Paidós.

Blanco, A. y Díaz, D. (2005). El bienestar social: su concepto y medición. Psicothema, 17(4), 582-589. http://www.psicothema. es/pdf/3149.pdf

Bradt, J., Biondo, J. \& Vaudreuil, R. (2019). Songs created by military service members in music therapy: A retrospective analysis. The Arts in Psychotherapy, 62, 19-27. http://dx.doi.org/10.1016/j.aip.2018.11.004

Bruscia, K. (1999). Modelos de improvisación en Musicoterapia. Victoria-Gasteiz: Agruparte.

Bruscia, K (2014). Defining music therapy (third edition). Barcelona: Barcelona Publishers.

Burns, D. S., Meadows, A. N., Althouse, S., Perkins, S. M. y Cripe, L. D. (2018). Differences between Supportive Music and Imagery and Music Listening during Outpatient Chemotherapy and Potential Moderators of Treatment Effects. Journal of Music Therapy, 55(1), 83-108. http://doi.org/10.1093/jmt/thy001

Cabral, M. C., Delgadillo, A. O., Flores, E. M. y Sánchez, F. A. (2014). Manejo de la ansiedad en el paciente pediátrico oncológico y su cuidador durante la hospitalización a través de Musicoterapia. Psicooncología, 11(2-3), 243-258. http://doi. org/10.5209/rev_PSIC.2014.v11.n2-3.47386

Calleja, M., Sanz, P. y Tárraga, R. (2016). Efectividad de la musicoterapia en el trastorno del espectro autista: estudio de revisión. Papeles del Psicólogo. 37(2), 152-160. http://www.papelesdelpsicologo.es/pdf/2700.pdf

Carrasco, J., González, I. y Cañizares, A. B. (2020). Beneficios de la musicoterapia como opción integrativa en el tratamiento oncológico. Psicooncología, 17(2), 335-355. https://doi.org/10.5209/psic.68812

Chen, X. J., Hannibal, N., Xu, K. \& Gold, C. (2014). Group music therapy for prisoners: Protocol for a randomised controlled trial. Nordic Journal of Music Therapy, 23(3), 224-241. http://doi.org/10.1080/08098131.2013.854268

Daykin, N. \& Bunt, L. G. K. (2015). Music as a resource for health and wellbeing. En Ingrid. Söderback (ed.), International Handbook of Occupational Therapy Interventions (pp. 825-829). Springer International Publishing. http://dx.doi.org/10.1007/9783-319-08141-0_60

De Juanas, Á., Limón, M. R. y Navarro, E. (2013). Análisis del bienestar psicológico. Pedagogía Social. Revista Interuniversitaria, 22, 153-168. https://doi.org/10.7179/PSRI_2013.22.11

Denzin, N. K. (1970). Sociological Methods: a sourcebook. Chicago. Aldine Publishing Company. 
Díaz, D., Rodríguez, R., Blanco, A., Moreno, B., Gallardo, I., Valle, C. y Van Dierendonck, D. (2006). Adaptación española de las escalas de bienestar psicológico de Ryff. Psicothema, 18(3), 572-577. https://www.redalyc.org/pdf/727/72718337.pdf

Escarbajal, A., Izquierdo, T. y López, O. (2014). Análisis del bienestar psicológico en grupos en riesgo de exclusión social. Anales de Psicología, 30(2), 541-548. https://doi.org/10.6018/analesps.30.2.156591

Everaert, J., Bronstein, M. V., Castro, A. A., Cannon, T. D. \& Joormann, J. (2020). When negative interpretations persist, positive emotions don't! Inflexible negative interpretations encourage depression and social anxiety by dampening positive emotions. Behaviour Research and Therapy, 124, 1-47. http://dx.doi.org/10.1016/j.brat.2019.103510

Fakhoury, N., Wilhelm, N., Sobota, K. F. \& Kroustos, K. R. (2017). Impact of Music Therapy on Dementia Behaviors: A Literature Review. The Consultant Pharmacist 32(10), 623-628. http://dx.doi.org/10.4140/TCP.n.2017.623

Fallek, R., Corey, K., Qamar, A., Vernisie, S. N., Hoberman, A., Selwyn, P. A., Fausto, J. A., Marcus, P., Kvetan, V. \& Lounsbury, D. W. (2020). Soothing the heart with music: A feasibility study of a bedside music therapy intervention for critically ill patients in an urban hospital setting. Palliative \& Supportive Care, 18(1), 47-54. http://dx.doi.org/10.1017/S1478951519000294

Fernández-Ballesteros, R., Zamarrón, M. D., López, M. D., Molina, M. A., Díez, J., Montero, P. y Schettini, R. (2010). Envejecimiento con éxito: criterios y predictores. Psicothema, 22(4), 641-647. http://www.psicothema.com/PDF/3779.pdf

García, C. R. V. (2005). El bienestar psicológico: dimensión subjetiva de la calidad de vida. Revista Electrónica de Psicología Iztacala, 8(2), 1-20. http://revistas.unam.mx/index.php/repi/article/view/19260/18262

Gaston, E. (1982). Fundamentos de la Musicoterapia. El Hombre y la música. En E. Thayer Gaston y otros. Tratado de musicoterapia. (pp. 27-49). Barcelona: Editorial Paidos Ibérica S.A.

Gilbertson, S. \& Aldridge, D. (2008). Music Therapy and Traumatic Brain Injury. A Light on a Dark Night. London and Philadelphia: Jessica Kingsley Publishers.

Gold, C., Wigram, T. \& Elefant, C. (2007). Musicoterapia para el trastorno de espectro autista. La Biblioteca Cochrane Plus, 4, 1-22. http://www.sld.cu/galerias/pdf/sitios/mednat/musicoterapia_para_el_trastorno_de_espectro_autista.pdf

Gómez, M. y Gómez, J. (2017). Musicoterapia y enfermedad de Alzheimer: efectos cognitivos, psicológicos y conductuales. Neurología, 32(5), 300-308. http://dx.doi.org/10.1016/j.nrl.2015.12.003

Guenoun, M. y De Pedro, J. E. (2014). ¿Puede la musicoterapia disminuir los niveles de ansiedad y de estrés de los pacientes sometidos a hemodiálisis durante sus sesiones? Evidentia: Revista de enfermería basada en la evidencia, 11(46). https://dialnet. unirioja.es/servlet/articulo? codigo $=4873908$

Guil, R., Zayas, A., Gil-Olarte, P., Guerrero, C., González, S. y Mestre, J. M. (2016). Bienestar psicológico, optimismo y resiliencia en mujeres con cáncer de mama. Psicooncología, 13(1), 127-138. https://doi.org/10.5209/rev_PSIC.2016.v13.n1.52492

Helvik, A. S., Jacobsen, G. \& Hallberg, L. R. (2006). Psychological well-being of adults with acquired hearing impairment. Disability and Rehabilitation, 28(9), 535-545. https://doi.org/10.1080/09638280500215891

Herkenrath, A. (2002). Musiktherapie und Wahrnehmung: Ein Beitrag der Musiktherapie zur Evalierung der Wahrnehmungsfähigkeit bei Patienten mit schweren Hirnverletzungen. En D. Aldridge and M. Dembski (eds.), Music Therapy World: Musiktherapie, Diagnostik und Wahrnehmung. (pp. 136-160). Witten: University Witten/Herdecke.

Hervás, G. (2009). Psicología positiva: una introducción. Revista Interuniversitaria de Formación del Profesorado, 66, $23-41$. https://www.redalyc.org/pdf/274/27419066003.pdf

Holden, S. K., Sheffler, J., Stewart, R., Thompson, S., Persson, J., Finseth, T., Sillau, S. \& Kluger, B. M. (2019). Feasibility of Home-Based Neurologic Music Therapy for Behavioral and Psychological Symptoms of Dementia: A Pilot Study. Journal of Music Therapy, 56(3), 265-286. http://dx.doi.org/10.1093/jmt/thz009

Keyes, C. L. M. (1998). Social well-being. Social Psychology Quarterly, 61, 121-140. https://www.jstor.org/stable/pdf/2787065. pdf

Köhler, F., Martin, Z. S., Hertrampf, R. S., Gäbel, C., Kessler, J., Ditzen, B. \& Warth, M. (2020). Music Therapy in the Psychosocial Treatment of Adult Cancer Patients: A Systematic Review and Meta-Analysis. Frontiers in Psychology, 11, 651-666. http://dx.doi.org/10.3389/fpsyg.2020.00651

Kwan, C. K. \& Clift, S. (2018). Exploring the processes of change facilitated by musical activities on mental wellness. Nordic Journal of Music Therapy. 27(2), 142-157. https://doi.org/10.1080/08098131.2017.1363808

Lacárcel, J. (2003). Psicología de la Música y de la emoción musical. Educatio Siglo XXI, 20, 213-226. https://revistas.um.es/ educatio/article/view/138

Lago, P. (2008). La música y la terapia: la musicoterapia. Música y educación: revista trimestral de pedagogía musical, 21(3) 75, 110-121. http://hdl.handle.net/11162/28517

Lam, H. L., Li, W. T. V., Laher, I. \& Wong, R. Y. (2020). Effects of Music Therapy on Patients with Dementia - A Systematic Review. Geriatrics, 5(4) 62, 1-14. http://dx.doi.org/10.3390/geriatrics5040062

Lombardo, E. (2013). Psicología positiva y psicología de la vejez. Intersecciones teóricas. Psicodebate, 13, 47-60. https://doi. org/10.18682/pd.v13i0.361

López, L. (2009). Music and child neurology: A developmental perspective. En R. Haas \& V. Brandes (eds.), Music That Works (pp.179-184). Viena: Editorial Springer. https://doi.org/10.1007/978-3-211-75121-3_12

López, A. (2015). Musicoterapia con adolescentes bajo medidas judiciales en régimen abierto. Música, Terapia y Comunicación, 35, 31-48. https://dialnet.unirioja.es/servlet/articulo?codigo $=5820874$

Low, M. Y., Lacson, C., Zhang, F., Kesslick, A. \& Bradt, J. (2020). Vocal Music Therapy for Chronic Pain: A Mixed Methods Feasibility Study. Journal of Alternative and Complementary Medicine, 26(2), 113-122. http://dx.doi.org/10.1089/acm.2019.0249 
Mandel, S. E., Davis, B. A. \& Secic, M. (2019). Patient satisfaction and benefits of Music Therapy services to manage stress and pain in the Hospital Emergency Department. Journal of Music Therapy, 56(2), 149-173. http://dx.doi.org/10.1093/jmt/thz001

Manzini, J. L. (2000). Declaración de Helsinki: principios éticos para la investigación médica sobre sujetos humanos. Acta bioethica, 6(2), 322-234. http://dx.doi.org/10.4067/S1726-569X2000000200010

Martí. P., Mercadal, M. y Solé, C. (2015a). La musicoterapia en oncología. Gaceta Mexicana de Oncología, 14(6), $346-352$. https://doi.org/10.1016/j.gamo.2015.11.013

Martí. P., Mercadal, M. y Solé, C. (2015b). Efecto de la musicoterapia en el estado anímico y calidad de vida de un grupo de mujeres supervivientes de cáncer de mama. Psicooncología, 12(1), 105-128. https://doi.org/10.5209/rev_PSIC.2015.v12.n1.48907

Martín, S., Strassburguer, K., Hernández, Y. y Barquín, E. (2013). Lesión Medular: Guía para el manejo integral del paciente con Lesión Medular crónica. Madrid: ASPAYM Madrid. https://www.codem.es/Adjuntos/CODEM/Documentos/Informaciones/ Publico/ffcd6ec4-ba0e-456d-a4e6-898519fedd06/AFE3D9D2-2478-49D8-97A1-E8D672190CE4/8145d334-906c-4dc68357-d3026d3c9e9c/file_Guia_manejo_in.pdf

Meadows, A., Burns, D. S. \& Perkins, S. M. (2015). Measuring Supportive Music and Imagery Interventions: The Development of the Music Therapy Self-Rating Scale. Journal of Music Therapy, 52(3), 353-375. http://doi.org/10.1093/jmt/thv010

Meléndez, J. C., Tomás, J. M. y Navarro, E. (2011). Actividades de la vida diaria y bienestar y su relación con la edad y el género en la vejez. Anales de Psicología, 27(1), 164-169. https://roderic.uv.es/bitstream/handle/10550/61318/060809.pdf

Montorio, I. e Izal, M. (1992). Bienestar psicológico en la vejez. Revista Española de Geriatría y Gerontología, 27(3), $145-154$.

Moreno, M. E., Rodríguez, M. C., Gutiérrez, M., Ramírez, L. Y. y Barrera, O. (2006). ¿Qué significa la discapacidad? Aquichan, 6(1), 78-91. https://aquichan.unisabana.edu.co/index.php/aquichan/article/view/82/168

Okun, M. A. \& Stock, W. A. (1987). Correlates and components of subjective well-being among the elderly. Journal of Applied Gerontology, 6, 95-112. https://doi.org/10.1177/073346488700600108

OMS (1946). Constitución de la Organización Mundial de la Salud. https://apps.who.int/gb/bd/PDF/bd48/basicdocuments-48th-edition-sp.pdf?ua=1\#page $=7$

Ortega, E., Esteban, L., Estévez, A. F. y Alonso, D. (2009). Aplicaciones de la Musicoterapia en educación especial y en los hospitales. European Journal of Education and Psychology, 2(2), 145-168. https://doi.org/10.30552/ejep.v2i2.22

Orton-Johnson, K. (2010). Ethics in Online Research; Evaluating the ESRC Framework for Research Ethics Categorisation of Risk. Sociological Research Online, 15(4) 13, 1-5. https://doi.org/10.5153/sro.2261

Osborne, N. (2012). Neuroscience and "real world" practice: music as a therapeutic resource for children in zones of conflict. Annals of the New York Academy of Sciences, 1252(1), 69-76. http://doi.org/10.1111/j.1749-6632.2012.06473.x

Oslé, R. (2011). Musicoterapia y Psicoterapia. Avances en Salud Mental Relacional, 10(2), 1-10. https://psiquiatria.com/bibliopsiquis/musicoterapia-y-psicoterapia

Overy, K., Nicolson, R. I., Fawcett, A. J. \& Clarke, E. F. (2003). Dyslexia and Music: Measuring Musical Timing Skills. Dyslexia 9(1), 18-36. http://doi.org/10.1002/dys.233

Palacios, A. y Romañach, J. (2006). El modelo de la diversidad. La Bioética y los Derechos Humanos como herramientas para alcanzar la plena dignidad en la diversidad funcional. La Coruña: Ediciones Diversitas-AIES. https://e-archivo.uc3m.es/ bitstream/handle/10016/9899/diversidad.pdf

Palacios, J. I. (2001). El concepto de musicoterapia a través de la historia. Revista Interuniversitaria de Formación Del Profesorado, 42, 19-31. https://www.redalyc.org/pdf/274/27404203.pdf

Park, N., Peterson, C. y Sun, J. K. (2013). La Psicología Positiva: Investigación y aplicaciones. Terapia psicológica, 31(1), 11-19. http://dx.doi.org/10.4067/S0718-48082013000100002

Pascual, L. F. (1998). Calidad de vida y demencia. Revista de Neurología, 26(152), 582-584. http://doi.org/10.33588/ rn.26152.981029

Poch, S. (2001). Importancia de la musicoterapia en el área emocional del ser humano. Revista Interuniversitaria de Formación del Profesorado, 42, 91-113. https://dialnet.unirioja.es/servlet/articulo?codigo=233619

Poquérusse, J., Azhari, A., Setoh, P., Cainelli, S., Ripoli, C., Venuti, P. \& Esposito, G. (2018). Salivary $\alpha$-amylase as a marker of stress reduction in individuals with intellectual disability and autism in response to occupational and music therapy. Journal of Intellectual Disability Research, 62(2), 156-163. http://dx.doi.org/10.1111/jir.12453

Rodríguez-Antigüedad, A. (2004). Enfermedades neurodegenerativas. MinusVal, 148, 17-19. https://sid.usal.es/idocs/F8/8.2.1.2139/148/minusval_148.pdf

Romero, M. (2012). Modelo Benenzon de Musicoterapia. Valencia: Edita Universidad Católica de Valencia.

Ruiz, J. A. (2012). Afectividad positiva y personalidad. En UNED (Eds.), Psicología de la personalidad (pp. 1-10). Editorial UNED.

Ryff, C. D. (1989a). In the eye of the beholder: Views of psychological well-being among middle-aged and older adults. Psychology and Aging, 4(2), 195-210. https://doi.org/10.1037/0882-7974.4.2.195

Ryff, C. D. (1989b). Happiness is everything, or is it? Explorations on the Meaning of Psychological Well-Being. Journal of Personality and Social Psychology, 57(6), 1069-1081. https://doi.org/10.1037/0022-3514.57.6.1069

Särkämö, T., Tervaniemi, M., Laitinen, S., Forsblom, A., Soinila, S., Mikkonen, M., Autti, T., Silvennoinen, H. M., Erkkilä, J., Laine, M., Peretz, I. \& Hietanen, M. (2008). Music listening enhances cognitive recovery and mood after middle cerebral artery stroke. Brain: a journal of neurology, 131(3), 866-876. http://doi.org/10.1093/brain/awn013 
Särkämö. T., Tervaniemi. M., Laitinen. S., Numminen. A., Kurki. M., Johnson. J. K. \& Rantanen. P. (2014). Cognitive. Emotional and Social benefits of regular musical activities in early dementia: randomized controlled study. The Gerontologist, 54(4). 634-650. https://doi.org/10.1093/geront/gnt100

Schwartzmann, L. (2003). Calidad de vida relacionada con la salud: aspectos conceptuales. Ciencia y enfermería, 9(2), 9-21. http://doi.org/10.4067/S0717-95532003000200002

Seoane, J. (1999). Estilos y tipos de calidad de vida en el Cuestionario Sevilla. Actas Españolas de Psiquiatría, 27(4), $245-249$. https://www.uv.es/seoane/publicaciones/Estilos_y_tipos_de_calidad_de_vida_en_el_Cuestionario_Sevilla.pdf

Silverman, M. J. (2014). Effects of family-based educational music therapy on acute care psychiatric patients and their family members: An exploratory mixed-methods study. Nordic Journal of Music Therapy, 23(2), 99-122. http://doi.org/10.1080/08 098131.2013 .783097

Soria, G., Duque, P. y García, J. M. (2011). Música y cerebro (II): evidencias cerebrales del entrenamiento musical. Revista de Neurologia, 53(12), 739-746. http://doi.org/10.33588/rn.5312.2011475

Talwar, N., Crawford, M. J., Maratos, A., Nur, U., Mcdermott, O. \& Procter, S. (2006). Music therapy for in-patients with schizophrenia: exploratory randomised controlled trial. The British journal of psychiatry, 189(5), 405-409. http://doi.org/10.1192/ bjp.bp.105.015073

The Pan American Health Organization Promoting Health in the Americas (2012). DECLARACION DE ALMA-ATA. Conferencia Internacional sobre Atención Primaria de Salud, Alma-Ata, URSS, 6-12 de septiembre de 1978. https://medicinaysociedad. files.wordpress.com/2011/06/declaracion-de-alma-ata.pdf

Theode, H. C. (2002). Testing for normality. New York: Marcel Dekker.

UNESCO (19 de octubre de 2005). Declaración universal sobre Bioética y Derechos Humanos. Conferencia General. http:// portal.unesco.org/es/ev.php-URL_ID=31058\&URL_DO=DO_TOPIC\&URL_SECTION=201.html

Vaillancourt, G. (2009). Música y Musicoterapia. Su importancia en el desarrollo infantil. Madrid: Narcea Ediciones.

Vargas, C. (2009). La Musicoterapia: la forma o estilo musical como tratamiento en los desórdenes psicoanímicos. ESCENA. Revista de las artes, 32(65), 55-60. https://revistas.ucr.ac.cr/index.php/escena/article/view/8304/7859

Werner, J., Wosch, T. \& Gold, C. (2016). Effectiveness of group music therapy versus recreational group singing for depressive symptoms of elderly nursing home residents. Nordic Journal of Music Therapy, 25(1), 83-83. http://doi.org/10.1080/080981 31.2016.1180067

World Federation of Music Therapy (1996). $8^{\circ}$ Congreso Mundial. Hamburgo 1996. https://voices.no/index.php/voices/article/ view/1961

Yanguas, J. J. (2006). Análisis de la calidad de vida relacionada con la salud en la vejez desde una perspectiva multidimensional. Madrid: Instituto de Mayores y Servicios Sociales (IMSERSO). http://envejecimiento.csic.es/documentos/documentos/ yanguas-analisis-01.pdf

Zubieta, E. M. y Delfino, G. I. (2010). Satisfacción con la vida, bienestar psicológico y bienestar social en estudiantes universitarios de Buenos Aires. Anuario de Investigaciones 15, 277-283. https://www.redalyc.org/pdf/3691/369139946018.pdf

Zubieta, E., Fernández, O. y Sosa, F. (2012). Bienestar, valores y variables asociadas. Boletín de Psicología, 106(1), 7-27. https:// www.uv.es/seoane/boletin/previos/N106-1.pdf

Zubieta, E., Muratori, M. y Fernández, O. (2012). Bienestar subjetivo y psicosocial: explorando diferencias de género. Salud \& Sociedad, 3(1), 66-76. http://pepsic.bvsalud.org/pdf/salsoc/v3n1/a05.pdf

\section{Anexo 1}

Tabla 4. Características Clínicas de los Usuarios/as

\begin{tabular}{|c|c|c|c|c|c|c|c|c|}
\hline Usuario/a & Sexo & Dependencia & Edad & Estudios & Diagnóstico & Etiología & $\begin{array}{c}\text { Tratamien- } \\
\text { to }\end{array}$ & $\begin{array}{c}\text { Codificación } \\
\text { Cie 10 }\end{array}$ \\
\hline 1 & $\mathrm{H}$ & Silla Ruedas & 44 & Ninguno & $\begin{array}{c}\text { Trquizofre- } \\
\text { esqual por } \\
\text { nia para- } \\
\text { noide }\end{array}$ & $\begin{array}{c}\text { Enfermedad } \\
\text { cerebro } \\
\text { vascular }\end{array}$ & $\begin{array}{c}\text { Terapia an- } \\
\text { tidepresiva } \\
\text { Relajación }\end{array}$ & F20.1 \\
\hline 2 & $\mathrm{H}$ & Sin silla & 37 & Ninguno & $\begin{array}{c}\text { Retraso } \\
\text { mental leve }\end{array}$ & $\begin{array}{c}\text { Sufrimiento } \\
\text { fetal peri- } \\
\text { natal }\end{array}$ & $\begin{array}{c}\text { Terapia an- } \\
\text { tidepresiva } \\
\text { Rehabilita- } \\
\text { ción mus- } \\
\text { cular }\end{array}$ & F70 \\
\hline
\end{tabular}




\begin{tabular}{|c|c|c|c|c|c|c|c|c|}
\hline 3 & $\mathrm{H}$ & Silla Ruedas & 40 & Primarios & $\begin{array}{c}\text { Retraso } \\
\text { mental li- } \\
\text { gero } \\
\text { Hemipare- } \\
\text { sia }\end{array}$ & $\begin{array}{c}\text { Discapaci- } \\
\text { dad intelec- } \\
\text { tual } \\
\text { Discapaci- } \\
\text { dad física }\end{array}$ & $\begin{array}{c}\text { Terapia an- } \\
\text { tidepresiva } \\
\text { Rehabilita- } \\
\text { ción mus- } \\
\text { cular }\end{array}$ & G81.9 \\
\hline 4 & M & Silla Ruedas & 60 & Ninguno & $\begin{array}{l}\text { Hemiplejia } \\
\text { izquierda }\end{array}$ & $\begin{array}{l}\text { Poliomieli- } \\
\text { tis infantil }\end{array}$ & $\begin{array}{l}\text { Terapia an- } \\
\text { tidepresiva } \\
\text { Rehabilita- } \\
\text { ción mus- } \\
\text { cular }\end{array}$ & G81 \\
\hline 5 & $\mathrm{H}$ & Silla Ruedas & 51 & Ninguno & $\begin{array}{l}\text { Hemiplejia } \\
\text { izquierda }\end{array}$ & $\begin{array}{c}\text { Trauma- } \\
\text { tismo } \\
\text { craneoen- } \\
\text { cefálico y } \\
\text { alteración } \\
\text { de la con- } \\
\text { ducta por } \\
\text { síndrome } \\
\text { orgánico de } \\
\text { la persona- } \\
\text { lidad } \\
\end{array}$ & $\begin{array}{l}\text { Terapia an- } \\
\text { tidepresiva } \\
\text { Rehabilita- } \\
\text { ción mus- } \\
\quad \text { cular }\end{array}$ & G81 \\
\hline 6 & $\mathrm{H}$ & Silla Ruedas & 47 & Primarios & $\begin{array}{c}\text { Encefalopa- } \\
\text { tía epilepti- } \\
\text { forme pos- } \\
\text { traumática } \\
\text { Trastorno } \\
\text { depresivo }\end{array}$ & $\begin{array}{l}\text { Trauma- } \\
\text { tismo cra- } \\
\text { neoencefá- } \\
\text { lico }\end{array}$ & $\begin{array}{l}\text { Terapia an- } \\
\text { tidepresiva } \\
\text { Relajación }\end{array}$ & $\begin{array}{l}\text { G93.4 } \\
\text { F34.1 }\end{array}$ \\
\hline 7 & $\mathrm{H}$ & Silla Ruedas & 49 & Ninguno & $\begin{array}{c}\text { Parálisis } \\
\text { cerebral } \\
\text { Tetraparesia }\end{array}$ & $\begin{array}{l}\text { Encefalo- } \\
\text { patía }\end{array}$ & $\begin{array}{l}\text { Rehabilita- } \\
\text { ción mus- } \\
\text { cular }\end{array}$ & F82 \\
\hline 8 & M & Silla Ruedas & 46 & Medios & $\begin{array}{l}\text { Ictus con } \\
\text { hemiplejia } \\
\text { Síndrome } \\
\text { depresivo }\end{array}$ & $\begin{array}{l}\text { Accidente } \\
\text { cerebro } \\
\text { vascular }\end{array}$ & $\begin{array}{l}\text { Terapia an- } \\
\text { tidepresiva } \\
\text { Relajación }\end{array}$ & $\begin{array}{l}\text { G81.9 } \\
\text { F34.1 }\end{array}$ \\
\hline 9 & $\mathrm{H}$ & Silla Ruedas & 48 & Primarios & $\begin{array}{c}\text { Soriasis } \\
\text { Trastorno } \\
\text { depresivo }\end{array}$ & $\begin{array}{l}\text { Síndrome } \\
\text { del cuidador } \\
\text { con dete- } \\
\text { rioro } \\
\text { Intento de } \\
\text { autolisis }\end{array}$ & $\begin{array}{l}\text { Terapia an- } \\
\text { tidepresiva }\end{array}$ & F34.1 \\
\hline 10 & M & Silla Ruedas & 53 & Ninguno & $\begin{array}{l}\text { Parálisis ce- } \\
\text { rebral infan- } \\
\text { til en forma } \\
\text { atáxica } \\
\text { Tetraparesia }\end{array}$ & $\begin{array}{l}\text { Alteración } \\
\text { de la coor- } \\
\text { dinación } \\
\text { con pérdida } \\
\text { de control }\end{array}$ & $\begin{array}{l}\text { Rehabilita- } \\
\text { ción mus- } \\
\text { cular }\end{array}$ & G80.4 \\
\hline
\end{tabular}

Fuente: Elaboración propia, a partir de los datos proporcionados por FEPAMIC.

\section{Anexo 2}

Tabla 5. Resumen resultado Autoaceptación

\begin{tabular}{|c|c|c|}
\hline Preguntas & Respuestas del grupo & f \\
\hline \multirow{4}{*}{$\begin{array}{c}\text { 1. ¿Cómo crees que te sentirías si } \\
\text { fueses más positivo? }\end{array}$} & Estoy bien. & 4 \\
\cline { 2 - 3 } & Soy así. & 3 \\
\cline { 2 - 3 } & Me sentiría mejor. & 2 \\
\cline { 2 - 3 } & Otras respuestas. & 1 \\
\hline
\end{tabular}




\begin{tabular}{|c|c|c|}
\hline \multirow{4}{*}{$\begin{array}{c}\text { 2. ¿Cómo crees que te sentirías si te } \\
\text { aceptases tal y cómo eres? }\end{array}$} & Me gustaría estar en mi casa. & 1 \\
\cline { 2 - 3 } & Estaría mejor. & 4 \\
\cline { 2 - 3 } & No pienso en ello. & 3 \\
\cline { 2 - 3 } & Lo mejor es aceptarme tal y como soy. & 1 \\
\cline { 2 - 3 } & Otras respuestas. & 1 \\
\hline \multirow{3}{*}{\begin{tabular}{c} 
3. ¿Te has sentido alguna vez orgu- \\
\cline { 2 - 3 }
\end{tabular}} & Me da igual. & 2 \\
\cline { 2 - 3 } & No pienso en ello. & 3 \\
\cline { 2 - 3 } & Sí, estoy orgulloso. & 2 \\
\hline
\end{tabular}

Fuente: Elaboración propia.

Tabla 6. Resumen resultado Autonomía

\begin{tabular}{|c|c|c|}
\hline Preguntas & Respuestas del grupo & $\mathbf{f}$ \\
\hline \multirow{3}{*}{$\begin{array}{l}\text { 1. ¿Cómo te sientes cuando expresas } \\
\text { tus propias opiniones? }\end{array}$} & Bien. & 4 \\
\hline & No me echan cuenta. & 4 \\
\hline & Otras respuestas. & 2 \\
\hline \multirow{3}{*}{$\begin{array}{l}\text { 2. ¿Cómo te sientes cuando piensas } \\
\text { que lo que haces está bien? }\end{array}$} & Siento tranquilidad. & 5 \\
\hline & Contento conmigo mismo. & 4 \\
\hline & Otras respuestas. & 1 \\
\hline \multirow{3}{*}{$\begin{array}{l}\text { 3. ¿Cómo te sientes cuando te despreo- } \\
\text { cupas de lo que la gente piensa de ti? }\end{array}$} & No quiero que se enfaden. & 7 \\
\hline & No me gusta que hablen de mí. & 2 \\
\hline & Otras respuestas. & 1 \\
\hline \multirow{2}{*}{$\begin{array}{l}\text { 4. ¿Cómo te sientes cuando impones tu } \\
\text { propia voluntad? }\end{array}$} & Lo hacen por mi bien. & 6 \\
\hline & Otras respuestas. & 4 \\
\hline
\end{tabular}

Fuente: Elaboración propia.

Tabla 7. Resumen resultado Relaciones Positivas

\begin{tabular}{|c|c|c|}
\hline Preguntas & Respuestas del grupo & $\mathbf{f}$ \\
\hline \multirow{3}{*}{$\begin{array}{l}\text { 1. ¿Cómo te has sentido comunicán- } \\
\text { dote y expresando tus sentimientos a } \\
\text { través de la música usando un lenguaje } \\
\text { no-verbal? }\end{array}$} & Me he sentido raro. & 5 \\
\hline & Me ha gustado. & 4 \\
\hline & Otras respuestas. & 1 \\
\hline \multirow{3}{*}{$\begin{array}{c}\text { 2. ¿Crees que has fomentado la amis- } \\
\text { tad a través del lenguaje no-verbal } \\
\text { como medio de compartir sentimien- } \\
\text { tos? }\end{array}$} & Creo que sí. & 6 \\
\hline & Es difícil. & 3 \\
\hline & Otras respuestas. & 1 \\
\hline \multirow{3}{*}{$\begin{array}{l}\text { 3. ¿Cómo crees que se puede demos- } \\
\text { trar a tus amigos que confías en ellos } \\
\text { para que ellos confíen en ti? }\end{array}$} & Tengo más amigos. & 7 \\
\hline & No hablando mal de ellos a otros. & 1 \\
\hline & Otras respuestas. & 2 \\
\hline
\end{tabular}


4. ¿Has encontrado en tus amigos la ayuda que necesitas?

\begin{tabular}{|c|c|}
\hline Sí, mis amigos me ayudan. & 5 \\
\hline No me ayudan. & 4 \\
\hline Otras respuestas. & 1 \\
\hline
\end{tabular}

Fuente: Elaboración propia.

Tabla 8. Resumen resultado Dominio del Entorno

\begin{tabular}{|c|c|c|}
\hline Preguntas & Respuestas del grupo & f \\
\hline \multirow{4}{*}{$\begin{array}{c}\text { 1. ¿Aceptas las responsabilida- } \\
\text { des de tus decisiones? }\end{array}$} & Yo hago las cosas bien. & 6 \\
\cline { 2 - 3 } & No hago muchas cosas. & 1 \\
\cline { 2 - 3 } & Otras respuestas. & 3 \\
\hline \multirow{2}{*}{$\begin{array}{c}\text { 2. ¿Cómo crees que te sentirías } \\
\text { dirigiendo tu propia vida? }\end{array}$} & Me siento bien. & 7 \\
\cline { 2 - 3 } & A mí me ayudan. & 2 \\
\hline \multirow{3}{*}{$\begin{array}{c}\text { 3. ¿Cómo haces frente a tus res- } \\
\text { ponsabilidades? }\end{array}$} & Otras respuestas. & 1 \\
\cline { 2 - 3 } & Siendo responsables. & 9 \\
\cline { 2 - 3 } & Me tienen que ayudar. & 1 \\
\hline \multirow{2}{*}{ 4. ¿Te gusta tu modo de vida? } & Otras respuestas. & 0 \\
\cline { 2 - 3 } & Sí, me gusta. & 10 \\
\hline
\end{tabular}

Fuente: Elaboración propia.

Tabla 9. Resumen resultado Crecimiento Personal

\begin{tabular}{|c|c|c|}
\hline Preguntas & Respuestas del grupo & $\mathbf{f}$ \\
\hline \multirow{3}{*}{$\begin{array}{l}\text { 1. ¿Sientes miedo y ansiedad ante } \\
\text { la enfermedad y la vida? }\end{array}$} & Sí, lo tengo. & 5 \\
\hline & No. & 3 \\
\hline & Otras respuestas. & 2 \\
\hline \multirow{3}{*}{$\begin{array}{l}\text { 2. ¿Cómo llegarías a conocerte } \\
\text { mejor? }\end{array}$} & No lo sé. & 4 \\
\hline & Yo me conozco. & 5 \\
\hline & Otras respuestas. & 1 \\
\hline \multirow{3}{*}{$\begin{array}{c}\text { 3. ¿Cómo te sentirías si tu vida } \\
\text { mejorase? }\end{array}$} & Mucho mejor. & 7 \\
\hline & Contento. & 1 \\
\hline & Otras respuestas. & 2 \\
\hline \multirow{3}{*}{$\begin{array}{l}\text { 4. ¿Tus experiencias te han hecho } \\
\text { cambiar lo que piensas de ti? }\end{array}$} & No. & 6 \\
\hline & Cuando hago cosas. & 2 \\
\hline & Otras respuestas. & 2 \\
\hline
\end{tabular}

Fuente: Elaboración propia. 
Tabla 10. Resumen resultado Propósito de Vida

\begin{tabular}{|c|c|c|}
\hline Preguntas & Respuestas del grupo & $\mathbf{f}$ \\
\hline \multirow{3}{*}{ 1. ¿Qué planes de futuro tienes? } & Quiero estar bien. & 4 \\
\hline & No tengo planes. & 3 \\
\hline & Otras respuestas. & 3 \\
\hline \multirow{3}{*}{ 2. ¿Qué esperas del futuro? } & Que me curen. & 5 \\
\hline & Ponerme bien. & 4 \\
\hline & Otras respuestas. & 1 \\
\hline \multirow{3}{*}{ 3. ¿Te ponen triste los problemas? } & A veces estoy triste. & 4 \\
\hline & No. & 4 \\
\hline & Otras respuestas. & 2 \\
\hline \multirow{3}{*}{ 4. ¿Qué te propones en tu vida? } & Vivir mejor. & 6 \\
\hline & Curarme. & 3 \\
\hline & Otras respuestas. & 1 \\
\hline
\end{tabular}

Fuente: Elaboración propia. 